2 Research Square
Preprints are preliminary reports that have not undergone peer review.

They should not be considered conclusive, used to inform clinical practice, or referenced by the media as validated information.

\title{
Effect of novel coronavirus disease 2019 infection on chronic kidney disease G1-G5, G5 Dialysis and G5 Transplantation
}

Fateme Shamekhi Amiri ( $\sim$ fa.shamekhi@gmail.com )

Imam Khomeini Hospital Complex, College of Medicine, National Tehran of University Medical Sciences, Tehran, Iran

Research Article

Keywords: COVID-19 nephropathy, cytokine, kidney failure, lymphocytopenia, n-COVID-19

Posted Date: December 4th, 2020

DOl: https://doi.org/10.21203/rs.3.rs-66274/v2

License: (c) (i) This work is licensed under a Creative Commons Attribution 4.0 International License. Read Full License 


\section{Abstract}

Background: The pneumonia caused by the 2019 novel coronavirus (SARS-CoV-2) is a highly infectious disease that causes lethal disease and multiorgan failure. The aim of this research is to investigate association between coronavirus disease 2019 (COVID-19) infection and kidney dysfunction.

Methods and Materials: In this retrospective study, sixty-eight patients with kidney dysfunction and COVID-19 infection were investigated. Clinical features, laboratory data at initial presentation, management and outcomes were collected.The paper has written based on searching PubMed Central and Google Scholar to identify potentially relevant articles. Median, percentage, mean \pm standard deviation (SD), two-tailed $t$ and chi-square and Cohen $\llbracket s-$ $\mathrm{d}$ tests were used for statistical analyses. Moreover, relative risk, odds ratio, pearson囚s correlation for statistical analyses were used.

Results: The average age of patients at time of diagnosis in COVID-19 nephropathy was $52.04 \pm 14.42$ years (ranging from 24 years to 88 years). There was not statistical significance correlation between lymphocytopenia and serum creatinine (SCr) in COVID-19 nephropathy $\left(R^{2}=0.063 ; p-v a l u e=\right.$ 0.33). Effect size of elevated IL-6 on decreased estimated glomerular filtration rate (eGFR) in COVID-19 nephropathy was assessed 0.656 (medium effect size). Relative risk and odds ratio of acute kidney disease (AKD) in COVID-19 nephropathy were assessed 0.57 and 0.4 , respectively ( $p$-value: 0.422 ). Correlation between SCr changes and time of emergent acute kidney injury (AKI), AKD and chronic kidney disease (CKD) was assessed with $\mathrm{R}^{2}$ of 0.0003 and p-value of 0.94 (not significant).

Conclusion: The present study revealed medium effect size of elevated IL-6 on decreased eGFR. Future clinical research is required for investigating novel unknown findings in COVID-19 nephropathy.

\section{Introduction}

Viral pneumonia by novel coronavirus-19 (SARS-CoV-2) has been emerged in December 2019 in Wuhan, Hubei province, China for the first times [1]. This new disease has been named novel coronavirus disease-2019 (nCOVID-19) by world Health Organization. Coronavirus belongs to coronaviridae family, Nidovirales order and reveals with crown-like projections on its surface. In the late 1960s, it has been isolated from patients with common cold and identified it as B814 by electron microscopy. This virus comprise alpha (a), beta (b), gamma (g) and delta (d) subgroups. The main reservoirs of virus include bats, palm civets, livestock and animals. These viruses were assumed to transmit among animals till outbreak of SARS in 2002 year in the Guangdong, china. Thereafter, outbreak of Middle East respiratory syndrome coronavirus (MERS) has been emerged in Middle Eastern countries. In recent outbreak in china, it was thought to have originated from the Hunan seafood market at Wuhan in china. Some have belief that this virus has evolved from an unknown species of bat at a Wuhan wet animal market in southern china. The patients were diagnosed with pneumonia of unknown etiology and were related to seafood market. Gradually, disease was increased th that region and it was detected in those had not gone a journey to seafood market and that time purposed possible of person-to-person transmission. Coronavirus is a single stranded (positive sense) ribonucleic acid (RNA) Betacoronavirus, enveloped (E-protein) with club shaped/pear shaped/petal shaped glycoprotein projections (S-protein). This virus is spherical or pleomorphic shape with 80-120 nm size and include spikes which are made hemagglutinin esterase. The S-protein mediates the viral attachment and entry to endoplasmic reticulum. SARS-CoV-2 maintains the classic coronavirus structure like the presence of spike protein and expression of other nucleoproteins, polyproteins and membrane proteins such as RNA polymerase, 3-chymotrypsin-like protease, papain-like protease, helicase, glycoprotein and accessory proteins. Pandemic flu phase include phases 1-3 that predominantly are animal infections and few human infections. Phase 4 comprise sustained human to human transmission and phase 3-6/pandemic with widespread human infection. In post peak there is possibility of recurrent events and in post pandemic there is disease activity at seasonal levels [2].

\section{Objectives}

\section{How this study might work}

SARS-CoV-2 (COVID-19) in persons with chronic comorbidities can lead to critical illness easily or cause death. Patients with underlaying disease e.g. cardiac, lung, liver and kidney damage are at higher risk of COVID-19 infection rather than healthy patients. End-stage kidney disease patients are not exceptional this rule due to immune system suppression and poor outcomes from this viral infection. Hence, close identification of association between this viral infection and kidney dysfunction leads to new mechanisms in pathogenesis and novel therapeutic agents. This work causes less spread and limitation of viral infection.

\section{Why does this research}

SARS-CoV infection evolved in china in 2002 year and then SARS-CoV-2 has been spreaded in Dec 2019. SARS-CoV-2 has been isolated in saliva, nasopharynx and lower respiratory tract samples. Viral RNA has been found in the plasma of $15 \%$ of the most severely affected patients and viral detection in stool raises the possibility of fecal transmission. Because rapid spread, asymptomatic nature and high mortality of this viral infection has been caused to obtain specific and more knowledge about disease to prevent this viral infection.

\section{Methods}

\section{Eligibility criteria}

\section{Type of studies}


The search identified 1391 full-text articles via electronic search in google scholar and PubMed central databases. Therefore total records of 1391 fulltext articles were screened and seven articles were deduplicated (1384). Then 202 full-text articles were eligible and 1182 articles were excluded due to not related subject. Therefore, 68 records in 43 published articles included and 159 articles were discarded due to non-case reports. These 43 articles included 68 case reports that were examined 68 patients of kidney disease with CoViD-19 infection. These participants were enrolled for systematic review and meta-analysis synthesis.

\section{Type of participants}

Patients with kidney dysfunction including acute kidney injury (AKI), acute kidney disease (AKD), chronic kidney disease (CKD) and kidney replacement transplants (KRT) that were infected to SARS-CoV-2 were enrolled in this research.

\section{Type of outcome measures}

\section{Primary outcomes}

Risk of AKI, AKD, CKD, kidney failure (KF) progression to kidney replacement therapy (KRT) and graft loss, ICU admission, mechanical ventilation and death were primary outcomes in this study.

\section{Secondary outcomes}

Urinary tract infection (UTI), decreased eGFR and elevated urinary albumin to creatinine ratio (UACR) for detecting proteinuria were secondary outcomes in this study.

\section{Information sources}

The paper has written based on advanced searching via PMC and Google Scholar databases to identify articles published since inception to May 2020.

\section{Search methods for identification of studies}

\section{Electronic search}

The mentioned search performed with search terms of kidney and CoViD-19, CoViD-19 nephropathy in this research.

\section{Searching other resources}

The author reviewed references of all included articles and performed handsearching of related journals to identify the additional relevant studies.

\section{Study selection}

The search strategy was used to obtain titles and abstracts of studies that might be relevant to the review. The 401 plus 990 titles and abstracts were screened via electronic search in PMC and Google Scholar by author, respectively. Total records of 1391 articles were screened and after deduplication 1384 articles identified. Of them, 1182 articles were excluded due to non-related subject, review articles, others and 202 full-text articles were considered for eligibility. However studies and reviews that might include relevant data or information on studies were retained initially. The 159 articles were excluded and then 43 published articles that were examined 68 patients with covid-19 infection and renal dysfunction were included for qualitative and quantitative synthesis.

\section{Data collection and analysis}

\section{Data extraction and management}

Data extraction was carried out by author and studies which reported in journals as non-English language were translated before assessment. Where more than one publication of a study existed, reports were grouped together and the publication with the most complete data was included.

\section{Data items}

All patients with clinical, laboratory and radiologic presentations of CoViD-19 infection and decreased eGFR with or without positive test for CoViD-19 in sputum, stool, urine, peritoneal dialysis fluid and tissue biopsy-proven specimens were considered in this research. Demographic and clinical features such as age, sex, different symptoms and physical signs were extracted from this study. Furthermore, biochemical variables of serum creatinine (SCr), eGFR, urine protein, nucleic acid testing as quantitative real time reverse transcriptase polymerase chain reaction (qRT-PCR) at initial presentation and following days, imaging, management and outcomes were collected.

\section{Definition of kidney dysfunction}

$\mathrm{AKI}, \mathrm{AKD}$ and CKD can form a continuum whereby initial kidney injury can lead to persistent injury eventually leading to CKD. AKI is defined as an abrupt decrease in kidney function occurring over 7 days or less whereas CKD is defined by the persistent of kidney disease for a period of $>90$ days. AKD is defined as acute or subacute damage and/or loss of kidney function for a duration of between seven and 90 days after exposure to an AKI initiating 
event. Recovery from AKI within $48 \mathrm{~h}$ of the initiating event typically heralds rapid reversal of AKI (16th ADQI consensus report of 2017). CKD is classified zero to seven stages (stages of $0,1,2,3 a, 3 b, 4$ and 5 ) according to estimated glomerular filtration rate (eGFR) and kidney damage such as proteinuria ( $>200 \mathrm{mg} /$ day or protein to creatinine ratio $>200 \mathrm{mg} / \mathrm{g}$ creatinine) or albuminuria (urinary albumin excretion $\geq 30 \mathrm{mg} /$ day or albumin to creatinine ratio $\geq 30 \mathrm{mg} / \mathrm{g}$ creatinine). eGFR is defined according to creatinine clearance (CrCl), CockGroft-Gault equation, modification of diet in renal disease (MDRD) and chronic kidney disease-epidemiology collaboration (CKD-EPI). $\mathrm{CrCl}$ in 24-hr urine collection is expressed using urine creatinine (mg per deciliter or micromole per liter) multiplication by urine volume (milliliter or liter) divided on plasma creatinine (milligram per deciliter or micromole per liter) multiplied 1440 and it $₫ s$ unit is expressed with milliliter per minutes $(\mathrm{ml} / \mathrm{min})$. Cockcroft-Gault equation is expressed as $\mathrm{CrCl}=(140-\mathrm{age})^{\prime} \mathrm{wt}$ divided on SCr' 72 ,

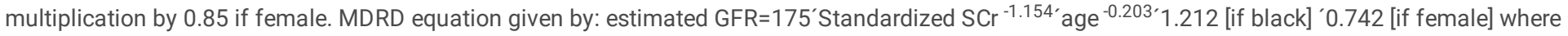
eGFR is expressed as $\mathrm{ml} / \mathrm{min} / 1.73 \mathrm{~m}^{2}$ of body surface area and SCr is expressed as $\mathrm{mg}$ per $\mathrm{dl}$. The CKD-EPI equation, expressed as a single equation, is

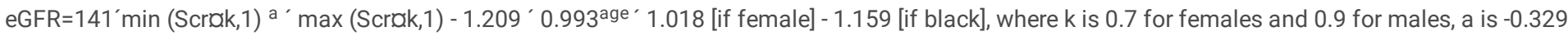
for females and 0.411 for males, min indicates the minimum Scrak or 1 and max indicates the maximum of Scrak or 1 . Proteinuria, albumin-to-creatinine ratio (ACR) is greater than $2.5 \mathrm{mg} / \mathrm{mmol}$ in men or $3.5 \mathrm{mg} / \mathrm{mmol}$ in women, or a protein-to-creatinine ratio (PCR) is greater than $15 \mathrm{mg} / \mathrm{mmol}$ is sufficient for diagnosis of CKD (random PCR < 15 mg/mmol: normal; 15-49 mg/mmol: trace proteinuria; 50-99 mg/mmol: significant proteinuria; $100-300$ $\mathrm{mg} / \mathrm{mmol}$ : high proteinuria; > $300 \mathrm{mg} / \mathrm{mmol}$ : nephrotic range proteinuria). Albuminuria may be classified as moderately increased albuminuria (3-30 $\mathrm{mg} / \mathrm{mmol}$ creatinine or severely increased albuminuria (greater than $30 \mathrm{mg} / \mathrm{mmol}$ creatinine). The normal PCR in children and adolescent is less than 0.3. In infants and younger children, the PCR is higher with the upper normal limit of 0.5. PCR above 3 is found in patients with nephrotic syndrome. The daily protein excretion rate (PER) can be determined from spot urine PCR, based on sex, age and weight using the following equations: PER $\left(\mathrm{g} / \mathrm{m}^{2} /\right.$ day $)=0.63^{*}(\mathrm{PCR})$.

\section{Definition of transmission of infection to others}

Person-to-person spread is thought to occur mainly via respiratory droplets. CoVid-19 virus RNA has been detected in blood and stool specimens. Through respiratory droplets generated by sneezing and coughing by infected person, generally when present in close proximity. By manual touching of infected surface (having the SARS-CoV-2 virus from symptomatic or asymptomatic person) and then hand touching the mouth, nose or eyes. Transmission do not occur through simple air (virus remain contained in sneezing droplets). No vertical mother-to-child transfer in case of pregnant women was seen [3].

\section{Definition of hyperpyrexia}

A morning readings $>37.2^{\circ} \mathrm{C}\left(98.9^{\circ} \mathrm{F}\right)$ or an afternoon temperature of $>37.7^{\circ} \mathrm{C}\left(99.9^{\circ} \mathrm{C}\right)$ would be considered a fever. Rectal temperatures are generally $0.6^{\circ} \mathrm{C}\left(1^{\circ} \mathrm{F}\right)$ higher than oral readings. Oral readings are lower probably because of mouth breathing, which is particularly important in patients with respiratory infections and rapid breathing. Tympanic membrane temperature readings are close to core temperature. The normal early morning to late afternoon daily increase is typically $0.5^{\circ} \mathrm{C}\left(0.9^{\circ} \mathrm{C}\right)$. However, in some individuals recovering from a febrile illness, this daily variation can be as high as $1.0^{\circ} \mathrm{C}$. During a febrile illness, the daily low early morning and high evening temperature difference is maintained but shifted upwards to higher levels. In menstruating women, the morning temperature is generally lower during the two weeks prior to ovulation, rising by about $0.6^{\circ} \mathrm{C}\left(1.0^{\circ} \mathrm{F}\right)$ with ovulation and remaining at that level until menses occur. Seasonal variation in body temperature has been described, but this may reflect a metabolic change and is not a common observation. Elevation in body temperature occurs during the postprandial state, but this is not fever. Pregnancy and endocrinologic dysfunction also affect body temperature. The daily temperature variation appears to be fixed in early childhood. On the other hand, it is well established that the ability to develop fever in older adults is impaired and that baseline temperature in older adults is lower than in younger adults. Thus, older adult patients with severe infections may only display a modest fever [4].

\section{Definition of tachycardia and tachypnea}

Equal or elevated heart rate of 100 beat per minute is defined as tachycardia and increased respiratory rate $>20$ breaths per minute is defined as tachypnea.

\section{Definition of Hypertension}

Based on the most recent American Heart Association/American College of Cardiology (AHA/ACC) guidelines, an office BP of less than $120 / 80$ is considered as normal and office BPs in the range 120 to $<130 / 80 \mathrm{mmHg}$ are considered to be elevated. An office BP of $140 / 90 \mathrm{mmHg}$ is thought to correlate with an ambulatory blood pressure monitoring (ABPM) in 24-hr with average BP of 130/80 mmHg (135/85 mmHg daytime and $120 / 70 \mathrm{mmHg}$ nighttime mean BPs) and home BP of $135 / 85 \mathrm{mmHg}$. Hypertension is defined as SBP ${ }^{3} 130$ and /or DBP ${ }^{3} 85$ mmHg or under medical treatment for hypertension.

\section{Clinical suspicion or criteria for CoViD-19 diagnosis}

Upto now, the possibility of CoVid-19 infection should be considered primarily in patients with fever and/or lower respiratory tract symptoms who reside in or have recently (within the prior 14 days) traveled to areas where community transmission has been reported (e.g. China, South Korea, Italy, Iran, Japan) or have had recent (within the prior 14 days) close contact with a confirmed or suspected cases of COVID-19. The possibility of COVID-19 should also be considered in patients with severe lower respiratory tract illness when an alternative etiology cannot be identified though has been no clear contact or exposure with infected patient [4]. 


\section{Definition of cell lineages in peripheral blood}

Leukocytosis is defined as a total WBC more than two standard deviations above the mean, or a value greater than 11000/microliter in adults. Leukopenia is defined as a total WBC less than $4400 /$ microliter in peripheral blood. Neutrophilic leukocytosis is defined as a total WBC above $11000 /$ microL along with an absolute neutrophil count (ANC) more than two standard deviations above the mean (greater than $7700 /$ microL in adults). Moreover, Neutrophilic leukocytosis is defined as neutrophil count more or equal than $75 \%$ in peripheral blood system (60 to $70 \%$ as normal percent). Lymphocytic leukocytosis is defined as a total WBC in excess of $11,000 / \mathrm{microL}$ primarily due to an absolute lymphocyte count in excess of $4800 / \mathrm{microL}$. Normal findings of this blood component is defined 20 to $40 \%$ and lymphocytosis is considered above $40 \%$. Other references defines this range $18-65 \%$ for 15 days- 5 months, $18-60 \%$ (6-23 months), 13-55\% (2-5 years), 13-50\% (6-11years), $13-45 \%$ (12-17 years) and 17-47\% (> 17 years). Proportions of lymphocytes below reference range is defined relative lymphocytopenia. An ANC $<1500 /$ microL $\left(<1.5 \times 10^{9} / \mathrm{L}\right)$ is the generally accepted definition of neutropenia for adults, as well as the threshold for neutrophil toxicity and infectious risk following chemotherapy. The normal range for the ANC varies somewhat with age. The lower limit of normal is $5000 / \mathrm{microL}\left(5.0 \times 10^{9} / \mathrm{L}\right)$ for the first week of life, then falls to $1000 / \mathrm{microL}\left(1.0 \times 10^{9} / \mathrm{L}\right)$ between two weeks and one year of age. Neutropenia is often categorized as mild, moderate or severe, based upon the level of ANC. Mild neutropenia corresponds to an absolute neutrophil count between 1000 and 1500/microL, moderate between 500 and 1000/microL, and severe with less than 500/microL.

Lymphocytosis is defined as an ALC $>4000$ cells /microliter (also expressed as $>4000 / \mathrm{mm}^{3}$ or $>4.0 \times 10^{9} / \mathrm{L}$ ). Lymphocytopenia has been variously defined in older children and adults as an ALC $<1000$ or $<1500$ cells/microL. Circulating blood lymphocytes include populations of T cells, B cells, and natural killer (NK) cells. Their normal relative proportions in the blood are: T cells (eg, CD ${ }^{+}$cells) -60 to 80 percent, B cells (eg, CD20 ${ }^{+}$cells) -10 to 20 percent, NK cells (eg, $\mathrm{CD}_{56}{ }^{+}$cells) - 5 to 10 percent. The normal relative proportions of $\mathrm{T}$ cell subtypes in the blood are: Helper/inducer $\mathrm{T}$ cells (ie, $\mathrm{CD} 4{ }^{+} \mathrm{T}$ cells) - 60 to 70 percent, Suppressor/cytotoxic T cells (ie, CD8 ${ }^{+} \mathrm{T}$ cells) -30 to 40 percent. Alanine aminotransferase (ALT) $>29$ to $33 \mathrm{IU} / \mathrm{L}$ in male and > 19 to $25 \mathrm{IU} / \mathrm{L}$ in female is defined abnormal serum aminotransferase levels. An aspartate aminotransferase (AST) cut off of 10 to 40 IU/L in for men and 9 to $32 \mathrm{IU} / \mathrm{L}$ in women is considered abnormal value. The normal range of lactate dehydrogenase (LDH) is between 140 to $280 \mathrm{U} / \mathrm{I}$. Normal serum albumin is defined 3.5-5.5 g/dl. Procalcitonine is a biologic marker that are sometimes used for distinguish between bacterial and nonbacterial causes of pneumonia. PCT is a peptide precursor of calcitonin that is released by paranchymal cells in response to bacterial toxins. It increases in bacterial infections and down-regulated in viral infections. It measures by kryptor assay and the immunoluminometric (LUMI) assay. Normal value for procalcitonine in males is $\leq 19 \mathrm{pg} / \mathrm{mL}$ or $\leq 19 \mathrm{ng} / \mathrm{L}$ [international system of units (SI units)] and $<0.5 \mathrm{ng} / \mathrm{ml}$. Amounts of less than $0.1 \mathrm{microgram}$ per liter $(\mathrm{mcg} / \mathrm{l})$ levels indicate nonantibiotic need and plasma levels above $0.25 \mathrm{mcg} / \mathrm{l}$ needs to antibiotic therapy. The reference range for C-reactive protein (CRP) is $<0.3 \mathrm{mg} / \mathrm{dl}$ or $<3 \mathrm{mg} / \mathrm{l}$ and for high-sensitivity CRP (hs-CRP) is $<3 \mathrm{mg} / \mathrm{l}$. Normal value for cytokine interleukin-2 receptor antagonist (IL- $2 \mathrm{Ra}$ ) level [cluster of differentiation (CD-25)] is $175.3-858.2 \mathrm{pg} / \mathrm{mL}$ and for IL-1b is $0.16-10 \mathrm{pg} / \mathrm{ml}$. Cytokine IL- 10 level in ages of 1 to 6 years is assessed 11.4 (9.5-12.8), age groups of 7 to 17 years is assessed 11.3 (8.9-13.7) and age groups of 318 years is assessed 12.6 (8.5-16.7) pg/ml. Cytokine IL- 8 level in ages of 1 to 6 years is assessed 30.9 (23.7-32), age groups of 7 to 17 years is assessed 32.6 (28.2-39) and age groups of 318 years is assessed $29.3(24.4-35.9) \mathrm{pg} / \mathrm{ml}$. level. Normal value for tumor necrosis factor-alpha (TNF-a) is $23-1500 \mathrm{pg} / \mathrm{ml}$. The reference range of cytokine IL-6 for a healthy population is less than $17.4 \mathrm{pg} / \mathrm{ml}$ (0-5.9). Normal value for d-dimer is $<500 \mathrm{ng} / \mathrm{ml} \mathrm{or} \mathrm{mcg/l} \mathrm{(mg/l),} £ 0.49 \mathrm{mg} / \mathrm{l}$ in healthy persons. Normal value for fibrinogen level in adult is $200-400 \mathrm{mg} / \mathrm{dL}$ or $2-4 \mathrm{~g} / \mathrm{L}$ (SI units). Normal serum creatin phosphokinase (CPK) is defined in amounts of $55-177$ units/l. In other references normal CPK is considered 21-232 IU/I in male adults and in female adults this amount is $21-215 \mathrm{IU} / \mathrm{I}$. Normal serum troponin I is $<0.04$ $\mathrm{ng} / \mathrm{ml}$ and probable heart attack is defined $>0.4 \mathrm{ng} / \mathrm{ml}$. Normal erythrocyte sedimentation rate (ESR) in male and female is defined based on following formula: age/2 in male and age $+10 / 2$ in female. Elevated ESR was seen in eight of sixty-eight patients $(8 / 68,11.7 \%)$ with mean average of in covid-19 nephropathy. The normal ferritin concentration ranges from 40 to $200 \mathrm{ng} / \mathrm{ml}$ (mcg/l). Normal serum sodium is $135-145 \mathrm{mEq} / \mathrm{l}$. Resting arterial oxygen saturation $\left(\mathrm{SaO}_{2}\right) \leq 95$ percent or exercise desaturation $\geq 5$ percent is considered abnormal.

\section{Definition of positive test for CoViD-19 infection}

Patients who meet the clinical criteria in above-mentioned should undergo testing for SARS-CoV-2 infection. Specimens can be collected from the upper respiratory tract (nasopharyngeal and oropharyngeal swab) and if possible the lower respiratory tract (sputum, tracheal aspirate, or bronchoalveolar lavage). Induction of sputum is not indicated. Additional specimens (e.g. stool, urine) can be collected. SARS-CoV-2 is detected by polymerase chain reaction (PCR). A positive test for SARS-CoV-2 confirms the diagnosis of COVID-19. If initial testing is negative but the suspicion for COVID-19 infection remains, the world health organization (WHO) recommends resampling and testing from multiple respiratory tract sites. Negative RT-PCR tests on oropharyngeal swabs despite computed tomography (CT) findings of viral pneumonia have been reported in some patients who ultimately tested positive for SARS-CoV-2. One important point that should be considered herein is continuation of shaded infected virus after improvement as such positive RTPCR tests for SARS-CoV-2 were reported in four laboratory-confirmed COVID-19 patients after they had clinically improved and tested negative on two consecutive tests. Serum immunoglobulin G (IgG) and immunoglobulin M (IgM) antibodies against SARS-CoV-2 are detected by colloidal gold immunochromatography assay (CGIC). This assay is against nucleocapsid (N) protein) and with some reactivity to the spike (S) protein. The sensitivity and specifity of this assay is 87.3 and $100 \%$, respectively. Serology may have an important role in diagnosing acute and past SARS infection [5].

\section{Assessment of risk of bias and quality in included articles}

Case reports were analyzed using criteria developed by the Joanna Briggs Institute Critical Appraisal tool for case reports that has different assessment tools for each study design in question. The evaluation tool has 8 items for case reports.

\section{Statistical analysis}


Data were entered in Microsoft Excel 2010 software. Categorical variables are recorded as frequency (N) and percentage (\%). The continuous variables were determined as to whether they were normally distributed using the kolmogorove-smirnov or shapiro-wilk test. Continuous variables with normal distribution reported as mean \pm standard deviation (SD). Nonparametric variables are expressed as median and interquartile range (Q1, Q3 and IQR). Comparisons between continuous variables with normally distributed (ND) data assessed by two-tailed one-sample t test analysis. Relative risk (RR) and Odds (Ods) ratio were used for assessing effect measures of risk factor on outcomes of disease. Furthermore chi-square test for association between risk factor (Covid-19) and outcomes was used. Effect size of intervention was assessed using Cohens $₫ \mathrm{~d}$ test. Correlation between two parametric and nonparametric variables were assessed using Pearson $₫$ s and spearson $₫$ s tests. This correlation between nonparametric $(\mathrm{X})$ and parametric $(\mathrm{Y})$ variables was assessed linear regression analysis. Significance was assessed with $p$-value of $<0.05$.

\section{Results}

\section{Description of studies}

\section{Results of the search and study selection}

After searching electronic databases author identified 1391 records. After duplicated articles were removed ( $N=7)$ and 1384 titles and abstracts screened, author discarded 1182 full-texts articles due to non-related subject. Then 202 articles were eligible and 159 articles were discarded due to not case reports. Of these, 43 published articles (68 case reports) were included and enrolled for participate in this study.

\section{Included studies (criteria)}

Forty-three published articles (68 case reports or participants) were considered for inclusion in this research.

\section{Study characteristics}

\section{Study design}

Randomized data were planned with systematic review and meta-analysis design in this retrospective study and those articles were collected via nonrandomized method.

\section{Sample sizes}

Sample sizes of 68 patients or participants were considered in this study.

\section{Setting}

Participants were referred to emergency room or local hospital in this research.

\section{Participants}

All patients included in this study had kidney diseases in relation with clinical, laboratory and radiologic features that had positive or negative test for CoViD-19 infection. The patients who had symptoms, signs, laboratory and radiologic characteristics of covid-19 nephropathy and elevated serum creatinine levels or decreased eGFR. Laboratory test for covid-19 included nucleic acid testing for RNA antigen of virus from upper/lower respiratory tract, blood, stool, urine, dialysate fluid and tissue.

\section{Excluded studies (criteria)}

Patients were excluded from the study if they had not kidney involvement at initial time or during follow up.

\section{Risk of bias and quality in the included studies}

Assessment of risk of bias and quality of included articles performed using Joanna Briggs Institute critical appraisal tools for case reports (Supplementary Table 1). Based on these criteria, sixteen of sixty-eight case reports obtained eight score (16/68, 23.5\%), thirty-one of sixty-eight case reports had seven score $(31 / 68,45.5 \%)$, twenty-one of sixty-eight case reports achieved to six score $(21 / 68,30.8 \%)$.

\section{Results of case studies}

\section{Patients' Characteristics}

Among screened 1391 full-text articles obtained in this research paper, 1182 articles were excluded due to unrelated subject, review articles and other studies. Then 202 full-text articles were eligible and 159 articles were excluded due to not case report ( $n=159)$. Finally 43 published articles were included in this study [6-48]. These 43 articles included 68 case reports that were examined 68 patients with clinical, laboratory and radiologic presentations of CoViD-19 infection and decreased eGFR with or without positive test for CoViD-19 in sputum, stool, urine, peritoneal dialysis fluid and tissue biopsyproven specimens who had renal dysfunction were considered for qualitative and quantitative synthesis in this research [Fig. 1]. Fifty of sixty-eight were male $(50 / 68,73.5 \%)$ and eighteen of those belonged to female sex $(18 / 68,26.4 \%)$. Twenty-three of sixty-eight patients (23/68, $33.8 \%)$ were from Wuhan 
province of China country, seven of sixty-eight patients from London of UK (7/68, 10.2\%), five of sixty-eight patients (5/68, $7.3 \%)$ from USA and Italy, three of sixty-eight patients from Iran, America from African race, South Korea and France (3/68,4.4\%), two of sixty-eight patients from Turkey and Netherland $(2 / 68,2.9 \%)$, one of sixty-eight patients from Zhengzhou province of China, Spain, Switzerland, America from Hendourasian ethnicity, Switzerland from African ancestry, Australia, West Africa, Brazil, Germany, Denmark, Sweden country and Shenzhen of China (1/68, 1.4\%). Causes of CoViD-19 nephropathy in this research were different that has been described in Table 2. The Mean average age of patients at time of diagnosis in CoViD-19 nephropathy was $52.04 \pm 14.42$ years (ranging from 24 years to 88 years). Of these, fifty patients (50/68, 73.5\%) were male and eighteen patients (18/68, $26.4 \%$ ) were female. Mean \pm SD age of patients in male and female levels at time of diagnosis in CoViD-19 nephropathy were $53.06 \pm 14.2$ old years (ranging from 24 to 88 years old) and $49.2 \pm 15$ (ranging from 27 years to 69 years), respectively. There was not statistical significance for age between two sex levels in covid-19 nephropathy (p-value: 0.36) [Supplementary Table 2].

\section{Patients Complaints}

The symptoms in this study were different and fifty-five patients (55/68, 80.8\%) presented with history of fever. Thirty-four patients (34/68, 50\%) presented with cough, twenty-one of sixty-eight patients with shortness of breath and fatique $(21 / 68,30.8 \%)$, fifteen of sixty-eight patients with diarrhea $(15 / 68,22.05 \%)$, fourteen of sixty-eight patients with dyspnea $(14 / 68,20.5 \%)$, thirteen of sixty-eight patients with dry cough (13/68, $19.1 \%)$, nine of sixtyeight patients with vomiting $(9 / 68,13.2 \%)$, seven of sixty-eight patients with abdominal pain and runny nose $(7 / 68,10.2 \%)$, five of sixty-eight patients with anorexia $(5 / 68,7.3 \%)$, four of sixty-eight patients with malaise and productive cough $(4 / 68,5.8 \%)$. There was history of hypertension in twenty-five of sixty-eight patients $(25 / 68,36.7 \%)$ with CoViD-19 nephropathy [Supplementary Table 3] [Fig.2]. In signs of CoViD-19 nephropathy, there were fever in forty-seven of sixty-eight patients $(47 / 68,69.1 \%)$. Moreover, there were high blood pressure in eleven of sixty-eight patients (11/68, $16.1 \%)$ in these patients. There were tachycardia in eleven patients of sixty-eight $(11 / 68,16.1 \%)$ and tachypnea in twelve of sixty-eight patients (12/68, $17.6 \%)$ of CoViD19 nephropathy. There were pulmonary edema, dehydration, abdominal tenderness and respiratory distress in two of sixty-eight patients (2/68, $2.9 \%$ ). Abnormal lung sounds were detected in six of sixty-eight patients $(6 / 68,8.8 \%)$ including ground glass opacities in the left lower lobe, mildly increased work of breathing and diffuse rhonchi, crackles in the right lower lung, a small infiltrate in right upper lobe, mild crackles in both lung fields and small pleural effusion and finally fine bilateral crackle. Elevated body mass index (BMI) were seen in three of sixty-eight patients with covid-19 nephropathy [Fig. 3] [Supplementary Table 4].

\section{Laboratory data}

There were leukopenia in ten of sixty-eight patients $(10 / 68,14.7 \%)$ with mean \pm SD of $3256 \pm 712.2 / \mathrm{ml}$, leukocytosis in five of sixty-eight patients $(5 / 68$, $7.3 \%$ ) with mean \pm SD of $15997 \pm 3350 / \mathrm{ml}$ and normal leukocytes in twenty-six of sixty-eight patients $(26 / 68,38.2 \%)$ that quantitated amount was not mentioned in one patient in this article. The mean average of normal leukocytes was assessed 7391.6 $\pm 1849.2 / \mathrm{ml}$ in CoViD-19 nephropathy. There were neutrophilia (count) in four of sixty-eight patients $(4 / 68,5.8 \%)$ and mean average of $13243 \pm 3767 / \mathrm{ml}$. Neutropenia was seen in one of sixty-eight patients $(1 / 68,1.4 \%)$. Normal neutrophil count was seen in twelve of sixty-eight patients $(12 / 68,17.6 \%)$ in peripheral blood of CoViD-19 nephropathy that quantitated amount was not mentioned in one patient in this article. The mean average of normal neutrophil count in eleven patients was assessed $5016 \pm 1242 / \mathrm{ml}$. Normal ALC was seen in eleven of sixty-eight patients $(11 / 68,16.1 \%)$ that quantitative amount were not mentioned in two patients in article. The mean average of normal lymphocyte count was assessed $1805 \pm 969 / \mathrm{ml}$. With consideration of normal peripheral lymphocytes about 30 to 40 percent in the circulating white cells, lymphopenia was seen in thirty-one of sixty-eight patients $(31 / 68,45.5 \%)$. Furthermore, quantitative amount was not mentioned in one patient and mean average of it was assessed of $584.6 \pm 226.1 / \mathrm{ml}$. Lymphocytosis was not seen in any of patients with CoViD-19 nephropathy. Neutrophilia as percentage was seen in five of sixty-eight (5/68, 7.3\%) patients with mean average of $84.25 \pm 5.56 / \mathrm{ml}$ [Fig. 4]. Elevated CRP with unit of $\mathrm{mg} / \mathrm{l}$ were seen in thirty-four of sixty-eight patients $(34 / 68,50 \%)$ with mean average of $79.16 \pm 87.47 \mathrm{mg} / \mathrm{l}$ and twelve of sixty-eight patients $(12 / 68,17.6 \%)$ using unit of $\mathrm{mg} / \mathrm{dl}$ with mean average of $22.30 \pm 39.38 \mathrm{mg} / \mathrm{dl}$ in CoViD-19 nephropathy. There were hypoalbuminemia in six of sixty-eight patients $(6 / 68,8.8 \%)$ with mean average of $2.68 \pm 0.39 \mathrm{~g} / \mathrm{dl}$. Elevated ALT was seen in eighteen of sixty-eight patients (18/68, 26.4\%) with mean average of $85.7 \pm 37.9 \mathrm{IU} / \mathrm{I}$ in CoViD-19 nephropathy. Elevated AST was seen in ten of sixty-eight patients $(10 / 68,14.7 \%)$ and average mean of $114.9 \pm 97.5 \mathrm{IU} / \mathrm{I}$. There were increased LDH in fifteen of sixty-eight patients $(15 / 68,22.05 \%)$ with mean average of $931.5 \pm 849.3$ IU/l. Serum PCT was measured in nine of sixty-eight patients $(9 / 68,13.2 \%)$ with CoViD-19 nephropathy that was elevated in four of sixty-eight patients $(4 / 68,5.8 \%)$ with mean average of $14.57 \pm 16.19 \mathrm{ng} / \mathrm{ml}$ but quantitification was not mentioned in a patient. Serum IL- 6 was measured in seventeen of sixty-eight patients (17/68, $25 \%$ ) with CoViD-19 nephropathy but there were elevated IL-6 in fourteen of sixty-eight patients (14/68, 20.5\%). Moreover, quantitative amount was not mentioned in one patient. The average mean of elevated IL- 6 was assessed $350.11 \pm 672.29 \mathrm{pg} / \mathrm{ml}$. There was elevated IL-1b in one of sixty-eight patients (1/68, $1.4 \%$ ) with CoViD-19 nephropathy. IL-8 was measured in two of sixty-eight patients (2/68, 2.9\%) with CoViD-19 nephropathy that was elevated in one of sixtyeight patients $(1 / 68,1.4 \%)$ [Table 1]. d-dimer was measured in seventeen of sixty-eight patients $(17 / 68,25 \%)$ with CoViD-19 nephropathy that was elevated in thirteen of sixty-eight patients (13/68, 20.5\%) with mean average of $5357.3 \pm 7563.3 \mathrm{ng} / \mathrm{ml}$. Serum creatinine was measured in fifty-one of sixty-eight patients $(51 / 68,75 \%)$ with covid-19 nephropathy. There was elevated serum creatinine in thirty-two of sixty-eight patients (32/68, $47.05 \%)$. Mean \pm SD of elevated SCr in these patients was assessed $2.44 \pm 1.28 \mathrm{mg} / \mathrm{dl}$. eGFR using Cr was measured in twenty-seven of sixty-eight patients (27/68, $39.7 \%$ ) that there was anuria in two patients and Mean \pm SD of eGFR was assessed $45.97 \pm 15.12 \mathrm{ml} / \mathrm{min} / 1.73 \mathrm{~m}^{2}$. Four of sixty-eight patients (4/68, $5.8 \%$ ) developed proteinuria in spot urinary protein to creatinine ratio (UPCR) sample and timed urine collection with mean average of $4.89 \pm 3.87 \mathrm{~g} / \mathrm{g} \mathrm{Cr}$ and $2.34 \pm 2.92 \mathrm{gr} / 24 \mathrm{hr}$, respectively. Moreover, one patient had two plus proteinuria in baseline urine analyses in this research (1/68, $1.4 \%)$. There was anemia in ten of sixty-eight of patients $(10 / 68,14.7 \%)$ with mean average of $9.48 \pm 1.8 \mathrm{~g} / \mathrm{dl}$ in CoViD-19 nephropathy. There were thrombocytopenia in seven of sixty-eight patients $(7 / 68,10.2 \%)$ that quantitative amount in one patient was not characterized in CoViD-19 nephropathy. The mean average of thrombocytopenia in six patients was assessed $102400 \pm 40636.2 / \mathrm{ml}$. Elevated fibrinogen was seen in seven of sixty-eight patients (7/68, $10.2 \%)$ and mean average of $682.3 \pm 168 \mathrm{mg} / \mathrm{dl}$ in covid-19 nephropathy. There were elevated serum CPK in five of sixty-eight patients (5/68, $7.3 \%)$ with mean average 
of $10990.7 \pm 17458.3 \mathrm{IU} / \mathrm{I}$ in CoViD-19 nephropathy. There were elevated serum troponin I in three of sixty-eight patients (3/68, $4.4 \%)$ with mean average of $0.84 \pm 0.41 \mathrm{ng} / \mathrm{ml}$ in CoViD-19 nephropathy. There were elevated ESR in eight of sixty-eight of patients $(8 / 68,11.7 \%)$ with mean average of $73.8 \pm 32.8$ $\mathrm{mm} / \mathrm{h}$ in CoViD-19 nephropathy. Elevated serum ferritin was seen in eleven of sixty-eight patients $(11 / 68,16.17 \%)$ and mean average of $7548.2 \pm 19472.5$ $\mathrm{ng} / \mathrm{ml}$ in covid-19 nephropathy. There were hyponatremia in eight of sixty-eight of patients $(8 / 68,11.7 \%)$ with covid-19 nephropathy with mean average of $128.7 \pm 6.4 \mathrm{mEq} / \mathrm{l}$. There was hypernatremia in one of sixty-eight patients $(1 / 68,1.47 \%)$ with covid-19 nephropathy. Hypocalcemia revealed in three of sixty-eight patients $(3 / 68,4.4 \%)$ with mean average of $6.76 \pm 1.69 \mathrm{mg} / \mathrm{dl}$ in covid- 19 nephropathy. Prolonged prothrombin time (PT) and partial thromboplastin time (PTT) were seen in two of sixty-eight patients $(2 / 68,2.9 \%)$ with covid-19 nephropathy. Hypoxemia was seen in twenty of sixty-eight patients $(20 / 68,29.41 \%)$ that quantitative amount was mentioned in fourteen patients with mean average of $88.56 \pm 12.56 \%$ in covid- 19 nephropathy. There was not statistical significance correlation between lymphocytopenia and SCr in covid-19 nephropathy $\left(R^{2}=0.063 ; p-v a l u e=0.33\right)$ [Fig.4]. Effect size of standardized mean difference of elevated IL- 6 on standardized mean difference decreased eGFR in covid-19 nephropathy was assessed 0.656 (medium effect size)

\section{Viral testing in this research}

Positive CoViD-19 testing of nasal, oropharyngeal, sputum, bronchoalveolar lavage fluid (BALF), blood, dialysate, peritoneal fluid and tissue samples of patients with SARS-CoV-2 in baseline time include thirty-three of sixty-eight of nasopharyngeal samples (33/68, 48.5\%), thirty of sixty-eight of oropharyngeal samples $(30 / 68,44.1 \%)$, three of sixty-eight in sputum samples $(3 / 68,4.4 \%)$, thirteen of sixty-seven patients from undetermined location $(13 / 68,19.1 \%)$, one of sixty-eight patients from peritoneal fluid $(1 / 68,1.4 \%)$. Tissue and blood samples for COVID-19 testing were obtained in two of sixty-eight cases $(2 / 68,2.9 \%)$ and nucleic acid testing of viral antigen resulted in negative $(1 / 68,1.4 \%)$ [Fig.5].

\section{Pathology}

Kidney biopsy was performed in three of sixty-eight patients $(3 / 68,4.4 \%)$ with CoViD-19 nephropathy that histologic characteristics were infavor of collapsing glomerulopathy. Apolipoprotein L1 (APOL1) genotyping on the biopsy material in one patient was found to be homozygous for the G1 risk allele. Other patient had APOL1 G0G2 in histologic kidney specimen [Supplementary Table 5].

\section{Imaging}

There were abnormal chest x-ray (CXR) in twenty-eight of sixty-eight patients (28/68, 41.1\%) with CoViD-19 nephropathy. Bilateral lung infiltration was seen in nineteen of sixty-eight patients $(19 / 68,27.9 \%)$ and one of sixty-eight patients $(1 / 68,1.4 \%)$ with unilateral lung infiltration. Unilateral pleural effusion was observed in three of sixty-eight patients $(3 / 68,4.4 \%)$ and bilateral pleural effusion in two of sixty-eight patients $(2 / 68,2.9 \%)$.There were nineteen of sixty-eight pulmonary lesions $(19 / 68,27.9 \%)$ in chest scan. These lesions in the lung include multiple or patchy opacities. Bilateral lung opacities, ground-glass, air bronchogram, nodular opacities as focal or diffuse or multiple were seen in chest CT scan. Abnormal transthoracic echocardiography (TTE) was seen in four of sixty-eight patients (4/68, 5.8\%) with covid-19 nephropathy. Renal ultrasound performed in two of sixty-eight patients $(2 / 68,2.9 \%)$ with covid-19 nephropathy [Supplementary Table 6].

\section{Treatment}

Drugs for therapeutic purposes of covid-19 nephropathy include entry inhibitors, replication inhibitors (Remdesivir), protease inhibitors (lopinavir/ritonavir), heterocyclic antivirals (chloroquine), nanodelivery drug systems, biological therapeutics and herbal drugs. Oxygen therapy was used in thirty-two of sixty-eight patients $(32 / 68,47 \%)$ with CoViD-19 nephropathy. Antibacterial therapies include moxifloxacin, amoxi-clav, ciprofloxacin, linezolid, Ceftaruline, meropenem, ceftriaxone, vancomycin, azithromycin, ceftazidime, cefepime, cefuroxime, amoxicillin, piperacillin-tazobactam, antituberculous agents, anti-malarial agents in this research [Fig.6]. Anti-hypertensive agents include losartan, lamipril, atenolol, nifedipine, olmesarten, hydralazine, clonidine, amlodipine, valsartan, lisinopril. Diuretics include furosemide, amiloride, sprinolactone, hydrochlorothiazide, immunosuppressive agents, corticosteroids and antiviral include ribavirin (5/68, 7.3\%), favipravir (2/68, 2.9\%), remdesivir (2/68, 2.9\%), lopinavir-ritonavir (15/68, 22.05\%), darunavir-cobicistat, arbidol or umifenavir (5/68, 7.3\%), oseltamivir (8/68, 11.7\%) [Fig.7], Anti-hypolipidemic agents, anticoagulative agents [(nadroparine, unfractionated heparin, warfarin, low molecular weight heparin (LMWH), enoxaparin], intravenous immunoglobulins ( Iv Igs), interferons (5/68, 7.3\%), corticosteroids, proton-pump inhibitors, anti-hypoglycemic agents, vasopressors, antithymoglobulin (ATG), thymoglobulin, anti-cytokines include tocilizumab $(9 / 68,13.2 \%)$, alemtuzumab, baxilizumab $(3 / 68,4.4 \%)$, rituximab, belatacept, eculizumab, corticosteroids, plasma exchange, mechanical ventilation. Non-invasive ventilation include personal protective equipment (PPE), continuous positive airway pressure (CPAP), positive end-expiratory pressure (PEEP), pronation, extracorporeal membrane oxygenation (ECMO) (6/68, 8.8\%), vitamins, IV voriconazole, tracheostomy, influenza vaccine, Glycyrrhizic acid, intubation, intensive care unit (ICU) admission (10/68, 14.7\%), lung protective ventilation, intensive therapy unit (ITU), etc. Renal replacement therapy (RRT) was performed for these patients that include twenty of sixty-eight patients (20/68, 29.4\%) on hemodialysis (HD), four patients on continuous venovenous hemodiafiltration (CVVHDF) (4/68,5.8\%), three patients on chronic renal replacement therapy (CRRT) (3/68, $4.4 \%)$, one patient on continuous venovenous hemofiltration (CVVH) and hemoperfusion (1/68, 1.4\%), three patients on RRT 3/68, 4.4\%), six patients on ECMO $(6 / 68,8.8 \%)$ and there were sixteen patients of KRTs $(16 / 68,23.5 \%)$. There was allogenic bone marrow (BM) transplantation in one of sixty-eight patients with covid-19 nephropathy $(1 / 68,1.4 \%)$. Thirteen of sixty-seven patients $(13 / 68,19.1 \%)$ underwent ventilator/respirator [Supplementary Table 7 ].

\section{Follow-up in patients with covid-19 nephropathy}

There were negative CoViD-19 testing in fifteen of sixty-eight patients $(15 / 68,22 \%)$ with covid-19 nephropathy during follow up (f/u). Positive CoViD-19 testing found in two of sixty-eight patients $(2 / 68,2.9 \%)$ with CoViD-19 nephropathy. There were elevated blood urea nitrogen (Bun) in one of sixty-eight 
patients $(1 / 68,1.4 \%)$ with covid-19 nephropathy. Elevated SCr was detected in fourteen of seventy-eight patients (14/68, 20.5\%) with covid-19 nephropathy and there were normal SCr in five of sixty-eight patients $(5 / 68,7.3 \%)$ with covid-19 nephropathy. There were normal CRP found in four of sixty-eight $(4 / 68,5.8 \%)$ patients with covid-19 nephropathy and elevated CRP was detected in six of sixty-eight patients (6/68, 8.8\%) with covid-19 nephropathy. Symptoms improved in eight of sixty-eight patients $(8 / 68,11.7 \%)$ with covid-19 nephropathy and decreased in four of sixty-eight patients $(4 / 68,5.8 \%)$. There were multiorgan failure (MOF) in one of sixty-eight patients $(1 / 68,1.4 \%)$ with nephropathy and symptom in one of sixty-eight patients was variable $(1 / 68,1.4 \%)$. There was 02 saturation ${ }^{3} 95 \%$ in four of sixty-eight patients $(4 / 68,5.8 \%)$ and 02 saturation of $90 \%$ found in two of sixty-eight patients $(2 / 68,2.9 \%)$ with covid-19 nephropathy. Resolution of CXR abnormalities found in four of sixty-eight patients (4/68, 5.8\%) and mild improvement found in two of sixty-eight patients $(2 / 68,2.9 \%)$ with covid-19 nephropathy. Furthermore, there was unresolved pulmonary abnormality in CXR in one of sixty-eight patients $(1 / 68,1.4 \%)$. There were unmentioned CXR during follow up in sixty-one of sixty-eight patients (61/68, 89.7\%) with covid-19 nephropathy. Fifteen of sixty-eight patients $(15 / 68,22 \%)$ with covid-19 nephropathy were expired during hospital course or follow up time. There were clear lungs in chest CT scan in three of sixty-eight patients $(3 / 68,4.4 \%)$ with covid-19 nephropathy during f/u. Leukocytosis and leukopenia found in two of sixty-eight of patients $(2 / 68,2.9 \%)$ with covid-19 nephropathy. Decreased LDH found in three of sixty-eight patients (3/68, $4.4 \%)$ with covid-19 nephropathy and elevated LDH was seen in two of sixty-eight patients $(2 / 68,2.9 \%)$ with covid-19 nephropathy. There were normal lymphocyte in one of sixty-eight patients $(1 / 68,1.4 \%)$ and elevated lymphocyte count in four of sixty-eight $(4 / 68,5.8 \%)$ patients with covid- 19 nephropathy during f/u. There was elevated d-dimer in two of sixty-eight patients $(2 / 68,2.9 \%)$ with covid-19 nephropathy. There was elevated procalcitonine in one of sixty-eight patients $(1 / 68,1.4 \%)$ with covid-19 nephropathy. There was decreased PT in one of sixty-eight patients (1/68, 1.4\%) with CoViD-19 nephropathy. Twentyone of sixty-eight patients $(21 / 68,30.8 \%)$ with covid-19 nephropathy were discharged from hospital. There were elevated ferritin in three of sixty-eight patients $(3 / 68,4.4 \%)$ with covid-19 nephropathy. Hypocapnia found in two of sixty-eight patients $(2 / 68,2.9 \%)$ with covid-19 nephropathy. Anemia found in three of sixty-eight patients $(3 / 68,4.4 \%)$ with covid-19 nephropathy. Hypofibrinogenemia found in two of sixty-eight patients (2/68, $2.9 \%)$ with covid-19 nephropathy. Ten of sixty-eight patients with covid-19 nephropathy stayed on HD during follow up and one of sixty-eight patients with covid-19 nephropathy remained on RRT but its type was not charactererized. One of sixty-eight patients stayed on dialysis treatment at time of writing of this report. ECMO continued in one of sixty-eight patients (1/68, 2.9\%) with covid-19 nephropathy during f/u [Supplementary Table 8].

\section{Outcomes}

\section{Primary end-points}

There was ICU admission in ten of sixty-eight patients (10/68, 14.7\%) with covid-19 nephropathy. There was need to mechanical ventilation in thirteen of sixty-eight patients $(13 / 68,19.1 \%)$ with covid-19 nephropathy. Fifteen of sixty-eight patients $(15 / 68,22 \%)$ died during hospital course or post-discharge. There were AKI in four of sixty-eight patients (4/68,5.8\%) with covid-19 nephropathy and AKD found in fourteen of sixty-eight patients (14/68, 20.5\%) with covid-19 nephropathy during follow up. Median and interquartile range of SCr during follow up were assessed 1.74 mg/dl and 1.18 mg/dl (Q3$\mathrm{Q} 1=2.73-1.55)$, respectively with midrange of 6.35 , minimum value of 1.25 and maximum value of $11.4 \mathrm{mg} / \mathrm{dl}$ during follow up. One of sixty-eight patients $(1 / 68,1.4 \%)$ had CKD during follow up. Effect size of covid-19 on AKI and AKD was assessed 0 and 0.003 using Cohen $\$ s-d test. Mean difference of $\mathrm{AKI}$ at baseline and follow up time was assessed -1.34 with $95 \%$ confidence interval (Cl) of -6.1089 to 6.108 . Comparison of two effect size using mean difference was calculated 0.464 with $95 \% \mathrm{Cl}$ of -5.47 to -0.232 . The mean average of SCr in AKD at baseline time was assessed $3.22 \pm 3.81 \mathrm{mg} / \mathrm{dl}$ with $95 \% \mathrm{Cl}$ of $1.0202-5.4198$ and mean average of SCr in AKD at follow up was assessed 3.155 $\pm 3.33 \mathrm{mg} / \mathrm{dl}$ with $95 \% \mathrm{Cl}$ of $-2.7099 ; 2.8499$. Mean difference of AKD at baseline and follow up time was assessed 1.48 with $95 \% \mathrm{Cl}$ of -457 to 3.016 . Comparison of two effect size using mean difference was calculated 0.019 with $95 \% \mathrm{Cl}$ of 1.23 to 5.07 .Ten of sixty-eight patients (10/68, $14.7 \%)$ were continued on HD and one of them was inserted on RRT and dialysis. Moreover, ECMO was doing for one of sixty-eight patients (1/68, 1.4\%) with covid-19 nephropathy. Relative risk and odds ratio of AKD in covid-19 nephropathy were assessed 0.57 and 0.4, respectively (p-value: 0.422 ). Upper and lower $\mathrm{Cl}$ included 0.04 and 3.9 in this research. In accordance with Cohen囚s "Rules of Thumb", effect size of it is equal with 0.4 (not effect). Correlation between SCr changes and time of emergent AKI, AKD and CKD was assessed with $\mathrm{R}^{2}$ of 0.0003 and p-value of 0.94 (not significant) [Fig. 8]. There were thirty-six of sixty-eight of KTRs (36/68, 52.9\%) in covid-19 nephropathy that ten of those $(10 / 68,14.7 \%)$ developed AKI due to acute rejection. Fourteen of sixty-eight patients (14/68, 20.5\%) underwent on different modalities of dialysis in hospital course and stayed on dialysis during follow up. One patient of sixty-eight patients underwent one session of HD.

\section{Secondary end-points}

Decreased eGFR found in eight of sixty-eight patients (8/68, 11.7\%) with mean average of $42.22 \pm 17.27 \mathrm{ml} / \mathrm{min} / 1.73 \mathrm{~m}^{2}$ in covid-19 nephropathy during follow up. 37.5\% of patients were in CKD G3b, 25\% in CKD G 2 and G IV, 12.5\% in CKD G3a in this research. Effect size of covid-19 on declined eGFR using Cohen's-d test was assessed 0.157 (trivial) and comparison between decreased eGFR of baseline time and follow up time using paired t-test was assessed 0.36 (not significant). There were proteinuria using spot UPCR in one of sixty-eight patients $(1 / 68,1.4 \%)$, three patients using 24 -hr urine collection $(3 / 68,4.4 \%)$ with mean average of $2.61 \pm 1.58 \mathrm{gr} / 24 \mathrm{hr}$ and one patient had trace proteinuria using urinalysis $(1 / 68,1.4 \%)$ with covid-19 nephropathy during follow up. UTI was seen in one of sixty-eight patients $(1 / 68,1.4 \%)$ with covid-19 nephropathy.

\section{Discussion}

Coronavirus belong to a big family of viruses that cause a wide range of diseases mainly related to respiratory system and infection may vary from common cold to more severe respiratory diseases. This virus may cause infection in other systems such as kidney, heart, brain and even cause multiorgan failure and culminate to death. Several factors can differentiate between viral and bacterial infections. In patients with lower respiratory tract infection, procalcitonine can serve as a helpful adjunct for guiding antibiotic therapy and resolving diagnostic uncertainty [4]. PCT is a marker for 
bacterial infection which induced by bacteriotoxin but suppressed by interferon. In this research, it was measured in nine of sixty-eight patients ( $9 / 68$, $13.2 \%)$ that was elevated in $7.3 \%$ (5/68) cases but was declined in one of sixty-eight cases. Of course, It should be talked that PCT in two of sixty-eight patients was be measured $(2 / 68,2.9 \%)$ and mortality was not seen in those cases. The pathogenesis of SARS is unknown but some reports believe that cytokine storm syndrome or cytokine release syndrome involves in its pathogenesis. These proinflammatory cytokines and chemokines include IL-6, TNFa, IL-1, IL-12, IL-8, interferon gamma. In CoViD-19, IL-2, IL-7, IL-6, IL-10, interferon gamma inducible protein 10 (IP10), monocyte chemoattractant protein (MCP1), macrophage inflammatory protein 1A and TNF-a are increased highly in serum levels of patients. Some are in belief that proinflammatory cytokines increase in proportional with disease severity and IL- 6 is an important key cytokine in this disease. Acute phase reactants in covid-19 nephropathy needs to specific consideration. Classification of acute phase reactants is dependent on the change in acute phase proteins (APPs) concentration. A 10-100-fold elevation is considered major; a 2-10-fold elevation is considered moderate; and a less than 2-fold elevation is considered minor. The APPs that elevated in major APRs include CRP and serum amyloid (SA); the APPs that elevated in a moderate APR include a1-acid glycoprotein (AGP); and the APPs that elevated in a minor APR include fibrinogen, haptoglobin (Hp) and ceruloplasmin (Cp). There are 8 proteins which are overexpressed in APRs denoted as 'positive' APPs, including Hp, SA, fibrinogen, Cp, AGP, a-1 antitrypsin (AAT), lactoferrin (Lf) and CRP. Similarly, there are a number of 'negative' APPs the expression levels of which are reduced, including albumin, transferrin and transthyretin. The APP is elicited by cytokines, including those functioning as positive and negative growth factors and cytokines with proinflammatory or anti-inflammatory activity. Positive or negative growth factor cytokines involved include: Interleukin (IL) -2; IL-3; IL-4; IL-7; IL-10; IL-11; IL-12; and granulocyte-macrophage colony stimulating factor. Proinflammatory cytokines involved include tumour necrosis factor (TNF)- $\alpha / \beta$; IL-1 $\alpha / \beta$; IL-6; IFN- $\alpha$ / $;$; IL-8; and macrophage inhibitory protein-1. Cytokines involved in the anti-inflammatory response include: IL-1 receptor antagonists; soluble IL-1 receptors; IL-1 binding protein; and TNF- $a$ binding protein. Moreover, ESR and ferritin increase in these patients. Covid-19 with hyperinflammatory pulmonary symptoms is associated with a cytokine storm involving interleukins and chemokine dysregulation. Of important cytokines is interleukin-6 [49]. One of achievements of this research is effect of elevated IL-6 on decreased eGFR and this effect on kidney failure can be substantial. In relation to this result, tocilizumab is recommended in severely infected cases with elevated IL- 6 in serum. In our research, tocilizumab has been used in $13.2 \%(9 / 68)$ of patients and two of sixty-eight patients (2/68, $2.9 \%)$ were expired. As such we know ceruloplasmin is one of positive APRs and associated cytokines include TNF-a, IL-1b and IFN-1. Other point in this research is usage of interferons that were used in six of sixty-eight patients (6/68, 8.8\%) and responsed to it in $7.3 \%$ cases (5/68). Angiotensin converting enzyme -2 (ACE2) is acellular receptor for SARS-CoV and SARS-CoV-2. ACE2 shares some homology with ACE but is not inhibited by angiotensin converting enzyme inhibitors (ACEIS). ACE2 is expressed in lung, heart, kidney and intestine as SARS-CoV-1, it may be hypothesized that chloroquine also interferes with ACE2 receptor glycosylation thus preventing SARS-CoV-2 binding to target cells. Different therapeutic modalities have been used in covid-19 nephropathy sofar. A recently case report described the beneficial effect of thalidomide (100 mg daily) plus low dose glucocorticoids [50]. Previously, Amirshahrokhi in an experimental study in mice showed thalidomide ameliorated the histological and biochemical lung alterations induced by parquet (PQ). Thalidomide decreased production of inflammatory and fibrogenic cytokine TNF-a, IL-1b, IL-6 and transforming growth factor-beta1 (TGF-b1). Moreover, myeloperoxidase (MPO) activity, nitric oxide (NO) and hydroxyproline content in lung tissue were declined [51]. Our study revealed the most common symptoms include history of fever (80.8\%) and cough (50\%) and the most common laboratory findings include elevated CRP (50\%) and lymphocytopenia (45.5\%) that frequency of symptoms and elevated CRP were in agreement with study by Pormohammad et al [52]. In our study there was male predominance to female gender $(73.5 \%$ vs. $26.4 \%)$ that is disagreement with study by Shang et al with female predominance versus (vs) male group ( $53 \%$ vs. $47 \%)[53]$.

\section{Conclusion}

Coronavirus, causing zoonotic infectious disease, belong to Nidovirales order, coronaviridae large family and coronavirinae subfamily. Preliminarily, CoVs are able to infect mammals and birds by causing various lethal diseases. Notably, following some genetic mutation, this virus has potential to lead in respiratory system from upper respiratory tract by resembling simple cold symptoms to lower respiratory tract such as bronchitis and pneumonia as well as SARS that both of these infections arising from human CoVs. In our research, there was not correlation between lymphocytopenia and elevated serum creatinine. Moreover, effect size of elevated IL-6 on decreased eGFR was medium. Relative risk and odds ratio of covid-19 in emerging acute kidney disease in covid-19 nephropathy was assessed 0.57 and 0.4 , respectively. Future research is needed for investigating more unknown findings about covid-19 nephropathy.

\section{Abbreviations}

ACR, albumin-to-creatinine ratio; AHA/ACC, American Heart Association/American College of Cardiology; ANC, absolute neutrophil count; BALF, bronchoalveolar lavage fluid; CKD-EPI, chronic kidney disease-epidemiology collaboration; $\mathrm{CrCl}$, creatinine clearance; KRT (kidney replacement therapy); KF (kidney failure); MDRD, modification of diet in renal disease; nCOVID-19 (novel coronavirus disease-2019); RNA (ribonucleic acid); PER, protein excretion rate; qRT-PCR, quantitative real time reverse transcriptase polymerase chain reaction; ITU, intensive therapy unit; WHO, world health organization.

\section{Declarations}

Acknowledgement: The author to wish thanks National University of Tehran Medical Sciences, College of Medicine and Imam Khomeini Hospital Complex. Moreover, the author offers this paper to all of health martyrs in world.

\section{Disclosure Statement}


Ethics Approval and consent to participate

Authors of published articles stated that research was conducted ethically in

accordance with the World Medical Association Declaration of Helsinki. They described that subjects (or their parents or guardians) were given their informed consent and study protocol was approved by the institute's committee on human research.

\section{Consent for publication}

Not applicable.

\section{Availability of data and material}

Author requested that the datasets become active in Figshare repository with DOI:10.6084/m9.figshare.12863882 after publication.

\section{Competing interests}

The author (s) declares that they have no competing interests.

\section{Funding}

Not applicable.

\section{Author contributions}

The author contributed in study concept, design, data collection, definition of intellectual content, literature search, clinical studies, data acquisition, data analysis, statistical analysis, manuscript preparation, manuscript editing, manuscript review and guarantor.

\section{References}

1. (Al-Ani AH)

2. (Samina M)

3. (Chhikara BS)

4. (K)

5. (T. J. Tang H)

6. (Tang B)

7. (Fu D)

8. (Ferry AJ)

9. (Huang J)

10. (Seminari E)

11. (Chen S)

12. (Bussalino E)

13. (Fontana F)

14. $(\operatorname{Kim~Y})$

15. (Banerjee D)

16. (Gilluen E)

17. (Karami P)

18. (Kissling S)

19. (Sharif-Razavi A)

20. (Zhu L)

21. (Marx D)

22. (Hartman ME)

23. (Rabdel J)

24. (Gaillard F)

25. (Vischini G)

26. (Wang R)

27. (Wang J)

28. (Larsen CP) 
29. (Suwanwongse K)

30. (Bartiromo N)

31. (X. X. Zhu L)

32. (MS)

33. (Meziyerh S)

34. (Chenna A)

35. (Deliwala S)

36. (Prattes J)

37. (Khatri A)

38. (Post A)

39. (Taghizadeh A)

40. (Cinar OE)

41. (Peleg Y)

42. (Rinaldi LF)

43. (Resch T)

44. (Bemtgen X)

45. (Arpali E)

46. (de Barros Machado DJ)

47. (Zeng JH)

48. (Lazareth $\mathrm{H}$ )

49. (Michot JM)

50. (Chen C)

51. (A. K)

52. (Pormohammad A)

53. (Tang H). (Shang J)

\section{Tables}

Table 1. Laboratory findings and statistical analysis of acute phase reactants and cytokines in covid-19 nephropathy. 
Percent (\%)

CRP: $42 / 68$

(61.7\%)

hs-CRP: $4 / 68$

(5.88\%)

Fibrinogen: 8/68

(11.7\%)

ferritin: 13/68

(19.11\%)

ESR:6/68 (8.8\%)

Nl CRP: 2/68

(2.9\%)

Nl hs-CRP: $1 / 68$

(1.4\%)

Nl C3: 2/68 (2.9\%)

C3: $1 / 68(1.4 \%)$

Nl C4: 3/68 (4.4\%)

Nl Albumin: 5/68

(7.3\%)

Hypoalbuminemia:

6/68 (8.8\%)

Nl IL-10: 2/68

(2.9\%)

IL-2R: 2/68 (2.9\%)

IL-6: $14 / 68$

(20.5\%)

Nl IL-1b: 2/68

(2.9\%)

Nl IL-8: 1/68

(1.4\%)

Nl TNF-a: $1 / 68$

(1.4\%)

\begin{tabular}{|c|c|c|c|}
\hline $\begin{array}{l}\text { Anti- } \\
\text { inflammatory } \\
\text { (IL-1RA, sIL- } \\
\text { 1Rs, IL1-BP, } \\
\text { TNF-a BP) } \\
\text { cytokines }\end{array}$ & $\begin{array}{l}\text { Proinflammatory } \\
\text { cytokines (TNF- } \\
\text { a/b, IL-1a/b, IL-6, } \\
\text { IFN-a/g, IL-8, } \\
\text { MIP-1) }\end{array}$ & $\begin{array}{l}\text { Positive } \\
\text { or } \\
\text { Negative } \\
\text { Growth } \\
\text { factor } \\
\text { cytokines } \\
\text { (IL-2, IL- } \\
\text { 3, IL-4, } \\
\text { IL-7, IL- } \\
10, \text { IL- } \\
11, \text { IL- } \\
12 \text {, } \\
\text { GMCSF) }\end{array}$ & $\begin{array}{l}\text { Negative APRs } \\
\text { (Albumin, } \\
\text { transferrin, } \\
\text { transthyretin) }\end{array}$ \\
\hline
\end{tabular}

GMCSF)
Positive APRs (Hp, SA

fibrinogen, Cp, AAT, AGP, APRs/cytokines CRP,

Lf,C2,C3,C4,C5,C9,Factor

B, C1 inhibitor, C4

binding protein), ESR,

ferritin

Case Reports

CRP (40mg/l)

CR1(Tang et al; 2020)

fibrinogen (522 $\mathrm{mg} / \mathrm{dl})$

CRP (200.18mg/l)

CR2 (Fu et al; 2020)

CR3 (Ferry et al; 2020)

CR4 (Huang et al; 2020)

CR5 (Huang et al; 2020)
IL-6 (26.22

$\mathrm{pg} / \mathrm{ml})$

$(4.23 \mathrm{~g} / \mathrm{dl})$

IL-6 $(86.3 \mathrm{pg} / \mathrm{ml})$

IL-6 (280.86

$\mathrm{pg} / \mathrm{ml}$ )
CRP (1.86 mg/dl)

CRP (74.34 mg/l),

fibrinogen
CR6 (Seminari et al; 2020)

CR7 (Chen et al; 2020)

CR8 (Chen et al; 2020) CR9 (Chen et al; 2020)

CR10

(Bussalino et al 2020)

CR11(Fontana et al; 2020)

Nl Albumin $\quad$ CRP $(4.6 \mathrm{mg} / \mathrm{dl})$

$(4.2 \mathrm{~g} / \mathrm{dl})$

Nl Albumin

(3.7g/dl)

CRP $(2.8 \mathrm{mg} / \mathrm{dl})$

CR12 (Kim et al; 2020)

CR13 (Kim et al; 2020)

CR14 (Banerjee et al; 2020)

CRP (83 mg/dl)

CR15 (Banerjee et al; 2020)
CRP (329 mg/dl)

CR16 (Banerjee et al; 2020)

CR17 (Banerjee et al; 2020)

CR18 (Banerjee et al; 2020)

CR19 (Banerjee et al; 2020)

CR20 (Banerjee et al; 2020)

Nl CRP (<0.5 mg/dl), fibrinogen $(741 \mathrm{mg} / \mathrm{dl})$
Nl Albumin $(3.1 \mathrm{~g} / \mathrm{dl})$

Nl IL-6 < 11 Nl IL-10 Hypoalbumi

$\begin{array}{ll}\mathrm{pg} / \mathrm{ml}, \text { IL-1b }(10 & (<3 \\ \mathrm{pg} / \mathrm{ml}) & \mathrm{pg} / \mathrm{ml})\end{array}$

$\begin{array}{ll}\mathrm{pg} / \mathrm{ml}, \mathrm{IL}-1 \mathrm{~b}(10 & (<3 \\ \mathrm{pg} / \mathrm{ml}) & \mathrm{pg} / \mathrm{ml})\end{array}$

CRP (31 mg/l), ESR (54 $\mathrm{mm} / \mathrm{h}$ ) ferritin (4254 mcg/l)
CR21(Guillen et al; 2020)

CR22 (Karami et al; 2020) CR23 (Kissling et al; 2020) $\mathrm{g} / \mathrm{l})$, Nl C4 (0.26 g/l), CRP (10 mg/dl), ESR (85 $\mathrm{mm} / \mathrm{h}$ )

CRP (30 mg/l)

CRP (80.5 mg/l)

CRP (118mg/l)

CRP (42.6 mg/l)
CR24 (SharifiRazavi; 2020) CR25 (Zhu et al; 2020) CR26 (Zhu et al; 2020) CR27 (Zhu et al; 2020) CR28 (Zhu et al; 2020) 
CRP (40 mg/l)

CRP (40.1 mg/l)

CRP (54 mg/l)

CRP (49.7 mg/l)

CRP (100.5 mg/l

CRP (34.1 mg/l)
IL-6 (29 pg/ml)

IL-6 (2436.7

$\mathrm{pg} / \mathrm{ml}$ )

IL-6 (74.3 pg/ml)

IL-6 (> 400

$\mathrm{pg} / \mathrm{ml})$
CRP (14 mg/l)

Hypoalbuminemia $(2.1 \mathrm{~g} / \mathrm{dl})$

Hypo $(2.9$ g/dl)
CRP (415 mg/l), ferritin

(1728 ng/ml),

CRP (9 mg/dl), fibrinogen $(885 \mathrm{mg} / \mathrm{dl})$, ferritin $(1385 \mathrm{ng} / \mathrm{ml}$ CRP (20.8 mg/dl), Nl fibrinogen $(183 \mathrm{mg} / \mathrm{dl})$, ferritin $(2052 \mathrm{ng} / \mathrm{ml})$ Fibrinogen $(741 \mathrm{mg} / \mathrm{dl})$

CR29 (Zhu et al; 2020)

CR30 (Zhu et al; 2020)

CR31(Zhu et al; 2020)

CR32 (Zhu et al; 2020)

CR33 (Zhu et al; 2020)

CR34 (Zhu et al; 2020)

CR35 (Marx et al; 2020)

CR36 (Hartman et al; 2020)

CR37 (Radble et al; 2020)

CR38 (Radble et al; 2020)

CR39 (Gaillard et al; 2020)

CR40 (Vischini et al; 2020) CR41(Wang et al ; 2020)

CR42 (Wang et al ; 2020)

CR43 (Wang et al ; 2020)

CR44 (Wang et al ; 2020)

CR45 (Wang et al ; 2020)

CRP (22.73 mg/l)

CRP (67 mg/l)

$\mathrm{Nl}$ albumin (4.67 $\mathrm{mg} / \mathrm{l}$ )

CRP (30.2 mg/l), ESR (35 mm/h)

$\mathrm{IL}-6(1$
$\mathrm{pg} / \mathrm{ml})$

Nl IL-10,

Nl IL-1b

IL-2R

$(<5 \mathrm{pg} / \mathrm{ml}), \mathrm{Nl}$ IL- $\quad$ IL-2R

(13.1pg/ml)

$\mathrm{U} / \mathrm{ml}$ )

IL-6 (25 pg/ml)

IL-6 (396 pg/ml)

IL-6 (616 pg/ml)
CRP (155.5 mg/l)

CRP (143 mg/l),ferritin (991ng/ml), ESR (64 $\mathrm{mm} / \mathrm{h}$ )

Nl CRP (8.7 mg/l), ferritin $(2724 \mathrm{ng} / \mathrm{ml})$ CRP (38.09 mg/l), ferritin $(251 \mathrm{ng} / \mathrm{ml})$

CRP (144 mg/dl), ferritin (465 ng/ml) CRP (11.85 mg/dl), ferritin (66165 $\mathrm{ng} / \mathrm{ml})$,

CRP (7 mg/dl), fibrinogen $(616 \mathrm{mg} / \mathrm{dl})$ CRP (33.4 mg/dl), fibrinogen $(920 \mathrm{mg} / \mathrm{dl}$ ESR $(46 \mathrm{~mm} / \mathrm{h})$
CR46 (Wang et al ; 2020; Euro Urol)

CR47 (Larsen et al; 2020

CR48

(Suwangwonse et al; 2020)

CR49

(Bartiromo et al; 2020) CR50 (Zhu et al; 2020; Euro Urol) CR51(Cappell et al; 2020)

CR52 (Meziyerh et al; 2020)

CR53 (Chenna et al; 2020)

CR54

(Deliwala; 2020)

CR55 (Prattes et al; 2020) CR56 (Khatri et al; 2020)

CR57 (Post et al; 2020) CR58 (Post et al; 2020) 
CR59

(Taghizadeh et al; 2020)

\begin{tabular}{|c|c|c|c|c|}
\hline \multicolumn{3}{|c|}{ IL-6 (72.2 pg/ml) } & \multirow{2}{*}{$\begin{array}{l}\text { hs-CRP }(18.81 \mathrm{mg} / \mathrm{dl}) \text {, } \\
\text { ferritin }(1868 \mathrm{mcg} / \mathrm{l}) \\
\text { CRP }(49.4 \mathrm{mg} / \mathrm{l}), \text { ferritin } \\
(1147 \mathrm{ng} / \mathrm{ml}), \text { ESR }(130 \\
\mathrm{mm} / \mathrm{h})\end{array}$} & \multirow{2}{*}{$\begin{array}{l}\text { CR60 (Cinar et } \\
\text { al; 2020) } \\
\text { CR61(Peleg et } \\
\text { al; 2020) }\end{array}$} \\
\hline $\begin{array}{l}\text { Nl IL-6 (12 } \\
\mathrm{pg} / \mathrm{ml})\end{array}$ & $\begin{array}{l}\text { IL-2R } \\
(1530)\end{array}$ & $\begin{array}{l}\text { Hypoalbuminemia } \\
(3.2 \mathrm{~g} / \mathrm{dl})\end{array}$ & & \\
\hline & & & hs-CRP (18.26 mg/dl) & $\begin{array}{l}\text { CR62 (Rinaldi } \\
\text { et al; 2020) }\end{array}$ \\
\hline & & & hs-CRP $(6.4 \mathrm{mg} / \mathrm{dl})$ & $\begin{array}{l}\text { CR63 (Bemtgen } \\
\text { et al; 2020) }\end{array}$ \\
\hline & & & CRP $(5.7 \mathrm{mg} / \mathrm{l})$ & $\begin{array}{l}\text { CR64 (Arpali et } \\
\text { al; 2020) }\end{array}$ \\
\hline \multirow[t]{4}{*}{$\begin{array}{l}\text { IL-6 (272.4 } \\
\mathrm{pg} / \mathrm{ml})\end{array}$} & & & $\begin{array}{l}\text { hs-CRP }(14.63 \mathrm{mg} / \mathrm{dl}), \mathrm{Nl} \\
\text { C3 (94) and C4 (40) }\end{array}$ & $\begin{array}{l}\text { CR65 (Machado } \\
\text { et al; 2020) }\end{array}$ \\
\hline & & & & $\begin{array}{l}\text { CR66 (Zeng et } \\
\text { al; 2020) }\end{array}$ \\
\hline & & & CRP (53 mg/l) & $\begin{array}{l}\text { CR67(Resch et } \\
\text { al; 2020) }\end{array}$ \\
\hline & & $\begin{array}{l}\text { Hypoalbuminemia } \\
(2.8 \mathrm{~g} / \mathrm{dl})\end{array}$ & $\begin{array}{l}\text { CRP }(92 \mathrm{mg} / \mathrm{l}) \\
\text { fibrinogen }(570 \mathrm{mg} / \mathrm{dl}) \text {, } \\
\text { ferritin }(2672 \mathrm{mcg} / \mathrm{l})\end{array}$ & $\begin{array}{l}\text { CR68 (Lazareth } \\
\text { et al; 2020) }\end{array}$ \\
\hline
\end{tabular}

APRs, acute phase reactants; AAT, a1-antitrypsin; AGP,a1-acid glycoprotein; Cp, ceruloplasmin; CRP, C-reactive protein; ESR, erythrocyte sedimentation rate; GM-CSF, granulocyte-macrophage colony stimulating factor; Hp, haptoglobin; hs-CRP, high sensitive C-reactive protein; Lf, lactoferrin; IL-1RAs, interleukin-1 receptor antagonists; IL-1 BP, interleukin-1 binding protein; IL-1Rs, interleukin-1 receptors; IL-1BP, interleukin-1 binding protein; IL-2Rs, interleukin-2 receptors; IFN-a, interferon-alpha; MIF-1, macrophage inflammatory protein-1; Nl, normal; SA, serum amyloid A; TNF-a, tumor necrosis factor-a; TNF-a BP, tumor necrosis factor-a binding factor.

Table 2. Causes of patients with covid-19 nephropathy. 


\section{Causes}

DM

KF, HTN, single kidney, Left nephrolithiasis

KF due to IgA nephropathy

AML-2

KF with unknown etiology

Kidney rejection due to IgA nephropathy

$\mathrm{KF}$, chronic GN

Unknown etiology

Unknown etiology

KF with unknown etiology

KF due to chronic interstitial nephritis

$\mathrm{KF}$ due to FSGS

$\mathrm{KF}$ due to DM

HTN

KF due to T1DM

ADPKD

KF due to Hypertensive nephrosclerosis and recurrent thromboembolic events

$\mathrm{KF}, \mathrm{DM}, \mathrm{HTN}$

Hereditary hemolytic anemia

Arterial HTN

KF due to IgA nephropathy

Unknown etiology

AKI, HTN

Unknown

Unknown

$\mathrm{CHF}, \mathrm{AF}$, chronic coronary disease

Unknown

HTN

HTN

Unknown

HTN, CHD

Unknown

HTN, HHD, COPD

HTN

Testicular cancer

HTN

Unknown, sHLH

T2DM, RA, Aortic aneurysm, Aplastic anemia

CKD stage 3 due to HTN, monoclonal gammopathy of unknown significance

Fibrillary GN

Hypertensive nephrosclerosis

Hypertensive nephrosclerosis

Chronic nephritis

Hypertensive nephrosclerosis

Hypertensive nephrosclerosis

DM

T2DM

HTN

Senior lock syndrome

Chronic GN

DM

KF due to unknown origin

Diabetic nephropathy

Infection

Diabetic nephropathy due to T1DM

HTN

HTN

Obstructive sleep apnea

AKI

MDS with FAB refractory anemia excess blast-1 subtype (MDS/RAEB-1), systemic Tb, associated

kidney disease

AKI

Infrarenal-AAA

AAA, HTN

Dilated CMP

CGN, chronic lupus-like syndrome

\section{Case Reports}

CR1 (Tang et al; 2020)

CR2 (Fu et al; 2020)

CR3 (Ferry et al; 2020)

CR4 (Huang et al; 2020)

CR5 (Huang et al; 2020)

CR6 (Seminari et al; 2020)

CR7 (Chen et al; 2020)

CR8 (Chen et al; 2020)

CR9 (Chen et al; 2020)

CR10 (Bussalino et al; 2020)

CR11 (Fontana et al; 2020)

CR12 (Kim et al; 2020)

CR13 (Kim et al; 2020)

CR14 (Banerjee et al; 2020)

CR15 (Banerjee et al; 2020)

CR16 (Banerjee et al; 2020)

CR17 (Banerjee et al; 2020

CR18 (Banerjee et al; 2020)

CR19 (Banerjee et al; 2020)

CR20 (Banerjee et al; 2020)

CR21(Guillen et al; 2020)

CR22 (Karami et al; 2020)

CR23 (Kissling et al; 2020)

CR24 (Sharifi-Razavi; 2020)

CR25 (Zhu et al; 2020)

CR26 (Zhu et al; 2020)

CR27 (Zhu et al; 2020)

CR28 (Zhu et al; 2020)

CR29 (Zhu et al; 2020)

CR30 (Zhu et al; 2020)

CR31 (Zhu et al; 2020)

CR32 (Zhu et al; 2020)

CR33 (Zhu et al; 2020)

CR34 (Zhu et al; 2020)

CR35 (Marx et al; 2020)

CR36 (Hartman et al; 2020)

CR37 (Radble et al; 2020)

CR38 (Radble et al; 2020)

CR39 (Gaillard et al; 2020)

CR40 (Vischini et al; 2020)

CR41 (Wang et al ; 2020)

CR42(Wang et al ; 2020)

CR43 (Wang et al ; 2020)

CR44 (Wang et al ; 2020)

CR45 (Wang et al ; 2020)

CR 46 (Wang et al ; 2020; Euro

Urol)

CR 47 (Larsen et al; 2020)

CR 48 (Suwangwonse et al;

2020)

CR 49 (Bartiromo et al; 2020)

CR 50 (Zhu et al; 2020; Euro

Urol)

CR 51(Cappell et al; 2020)

CR 52 (Meziyerh et al; 2020)

CR53 (Chenna et al; 2020)

CR 54 (Deliwala; 2020)

CR 55 (Prattes et al; 2020)

CR 56 (Khatri et al; 2020)

CR57 (Post et al; 2020)

CR58 (Post et al; 2020)

CR 59 (Taghizadeh et al; 2020)

CR60 (Cinar et al; 2020)

CR61(Peleg et al; 2020)

CR62 (Rinaldi et al; 2020)

CR63 (Resch et al; 2020)

CR64 (Bemtgen et al; 2020)

CR65 (Arpali et al; 2020) 
AAA, abdominal aortic aneurysm; ADPKD, autosomal dominant polycystic kidney disease; AF, atrial fibrillation; AKI, acute kidney injury; AML-2, acute myeloid leukemia-2; CGN, chronic glomerulonephritis; CHD, chronic coronary disease; CKD, chronic kidney disease; CMP, cardiomyopathy; COPD, chronic obstructive pulmonary disease; DM, diabetes mellitus; FSGS, focal segmental glomerulosclerosis; GN, glomerulonephritis; HCV, hepatitis virus C; HHD, hemophagocytosis; HTN, hypertension; IgA, immunoglobulin A; KF, kidney failure; MDS/RAEB-1, myelodysplastic syndrome/refractory anemia with excess blast; RA, rheumatoid arthritis; sHLH, secondary hemophagocytic lymphohistiocytosis; T2DM, type-2 diabetes mellitus.

Figures

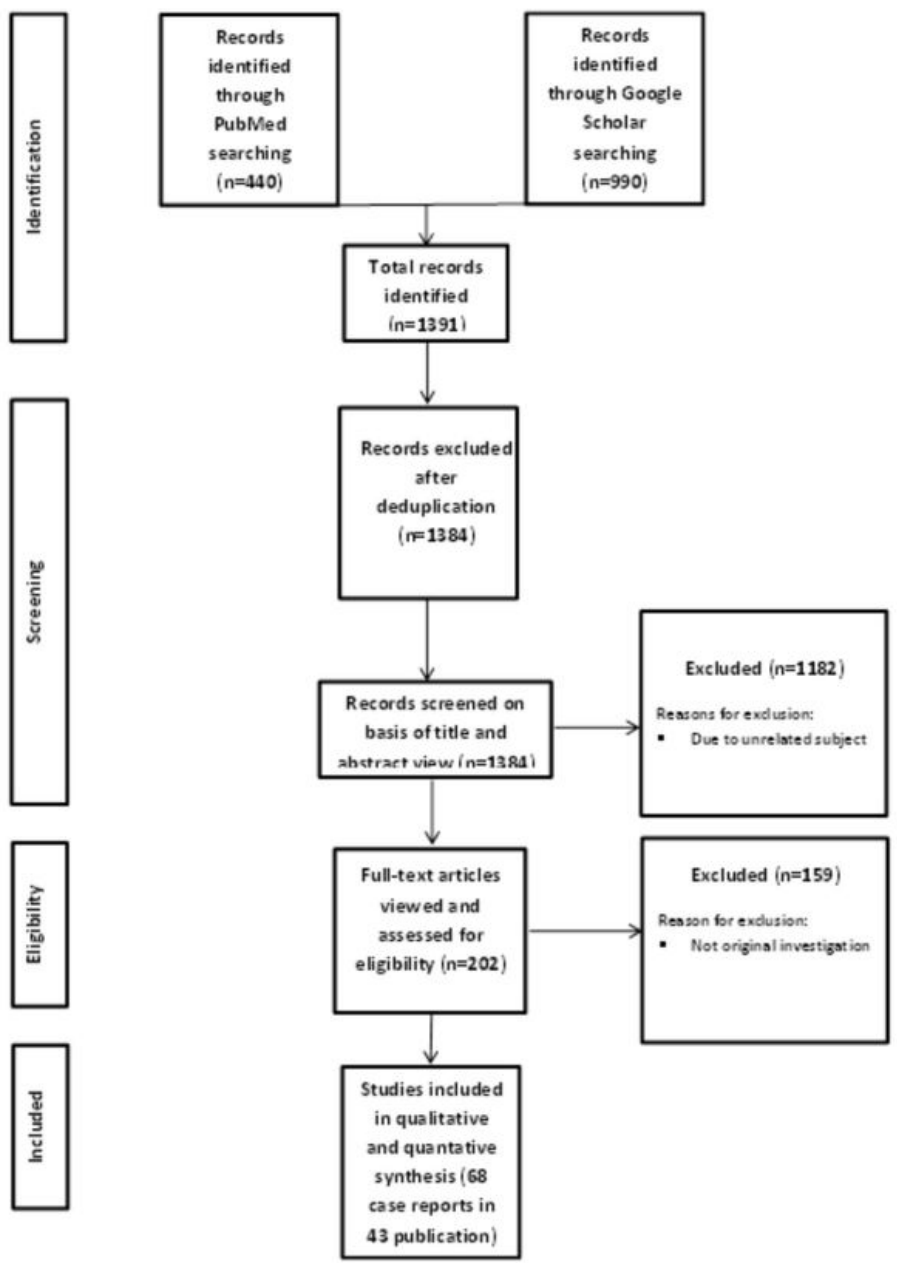

Figure 1

Workflow of included studies. 


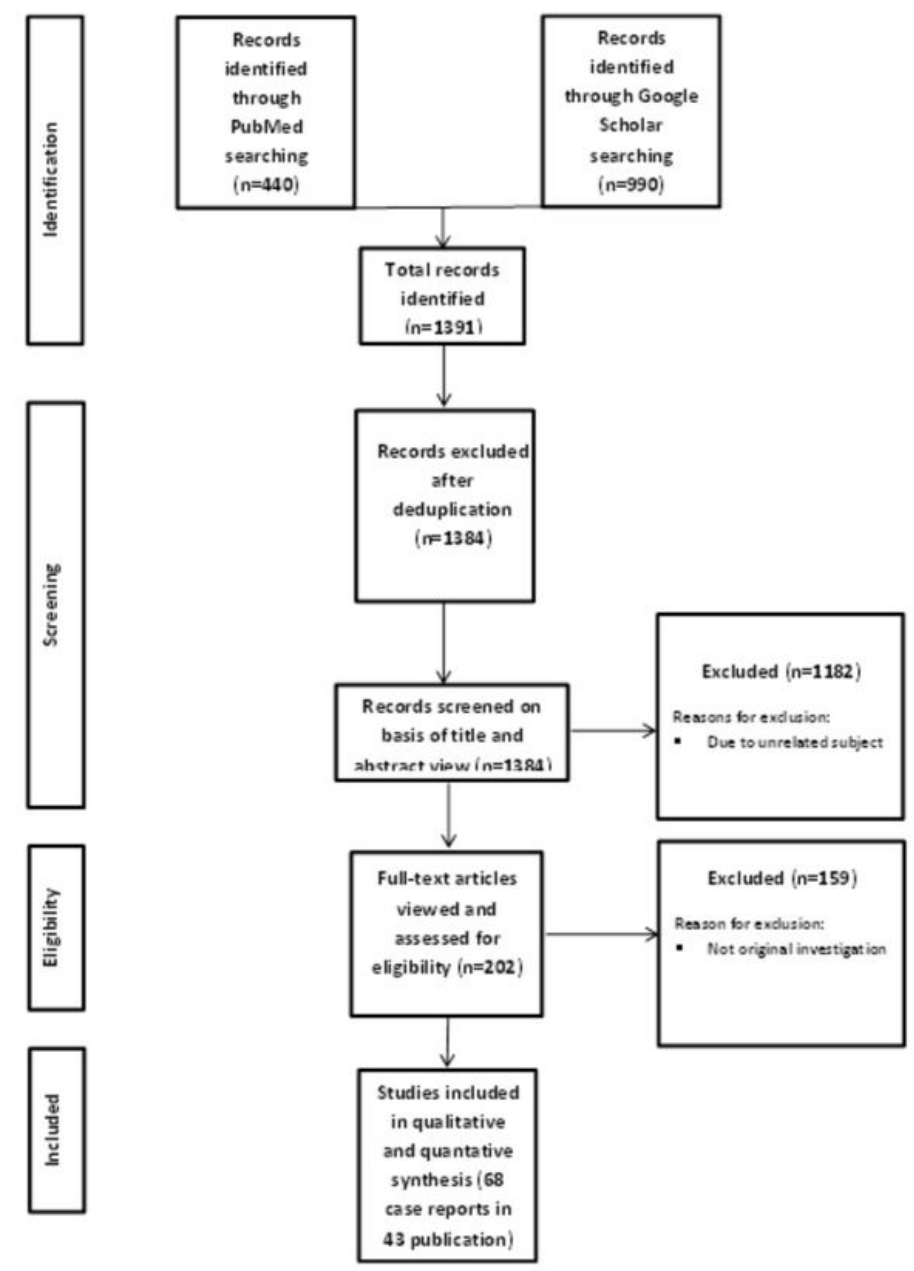

Figure 1

Workflow of included studies. 

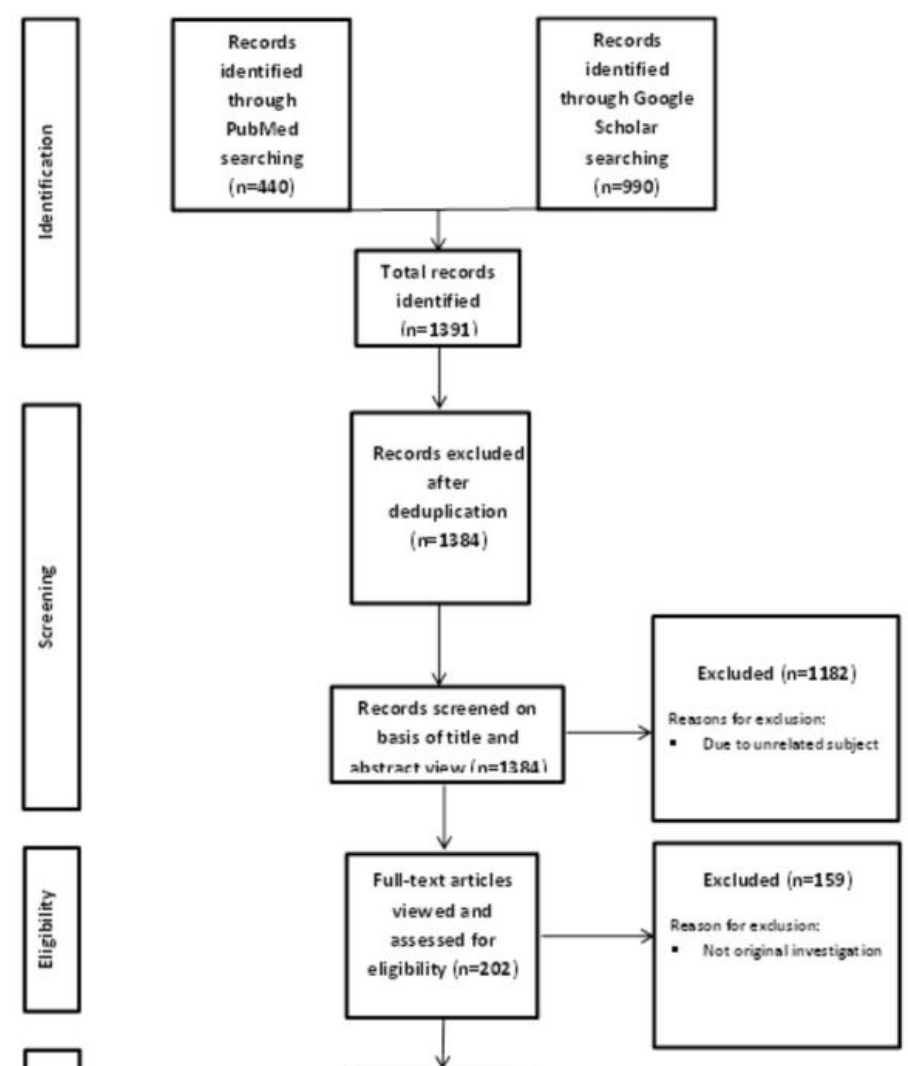

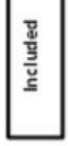

Studies included in qua litative and quantative

synthesis (68

case reports in

43 publication)

Figure 1

Workflow of included studies. 


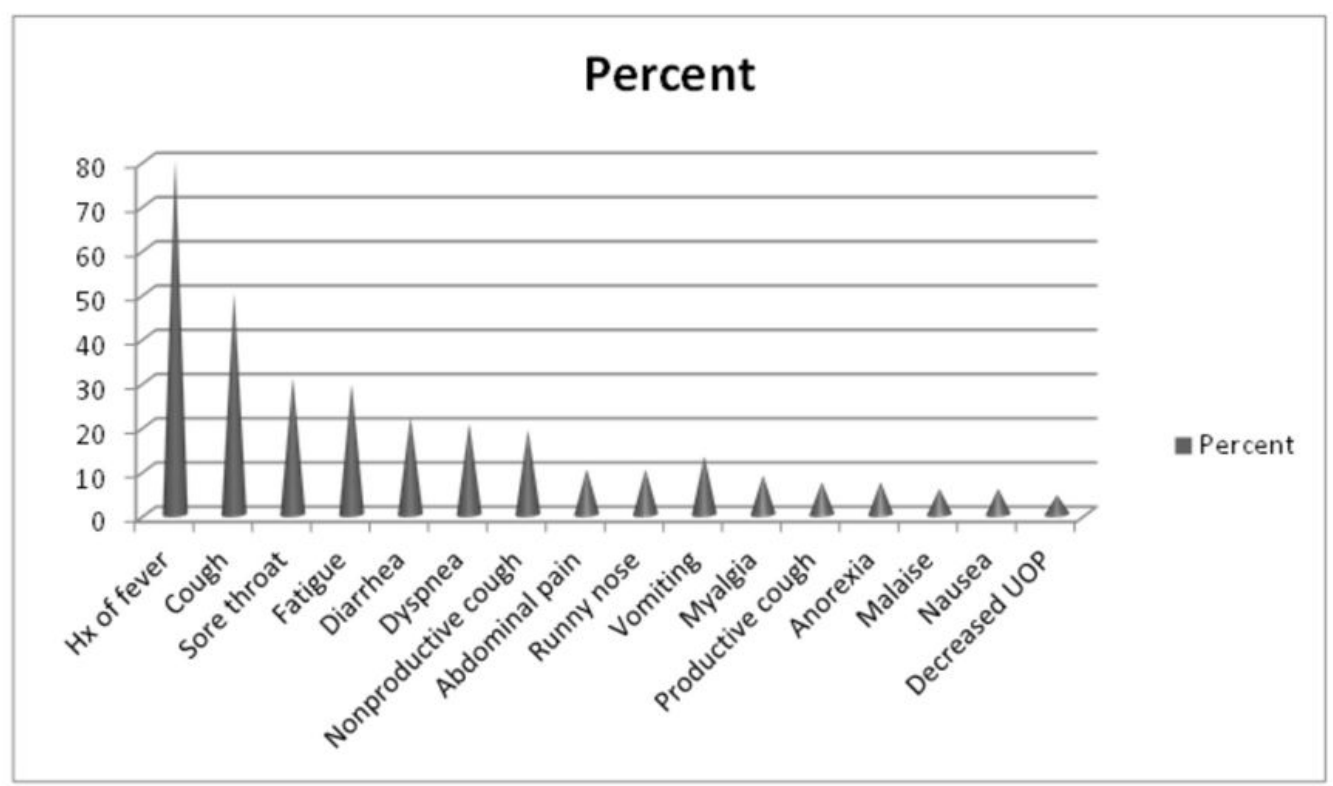

Figure 2

Distributional diagram of symptoms in patients with covid-19 nephropathy. 


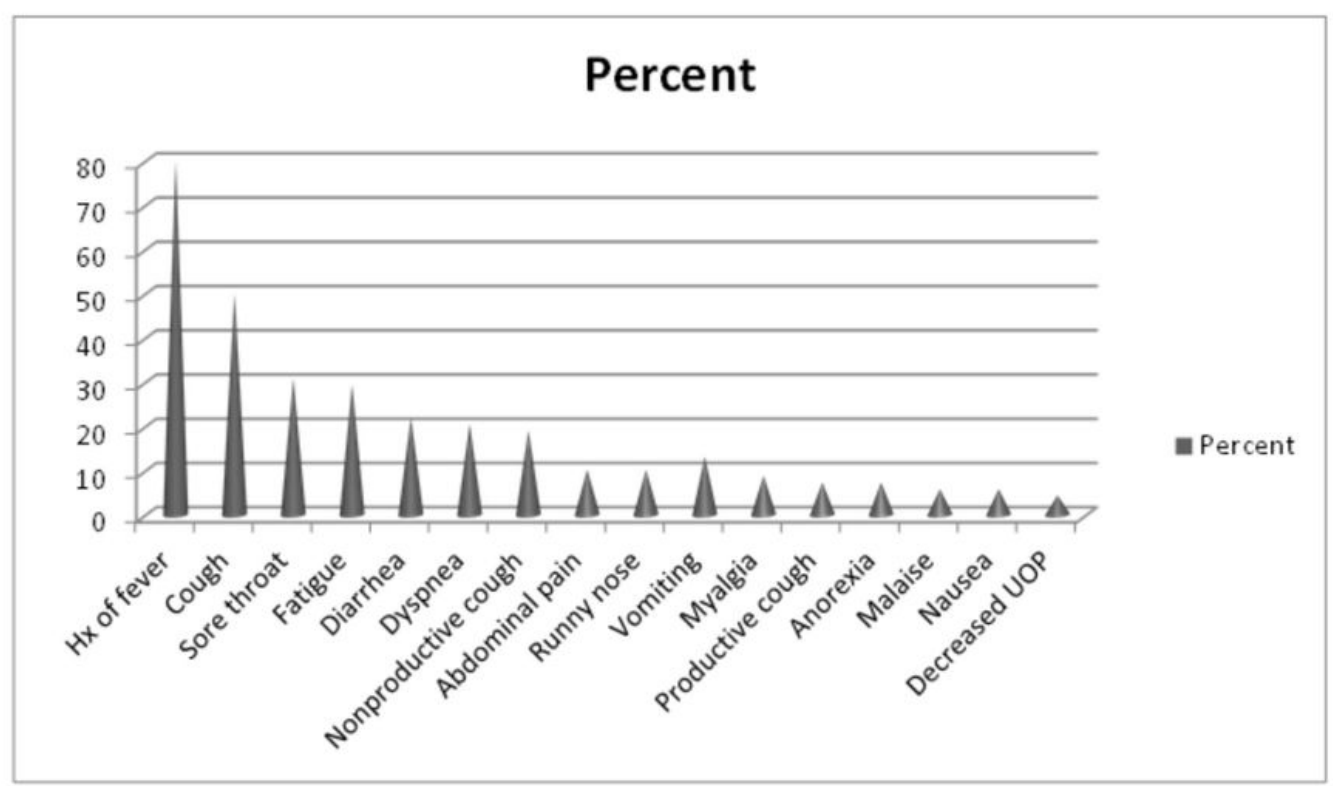

Figure 2

Distributional diagram of symptoms in patients with covid-19 nephropathy. 


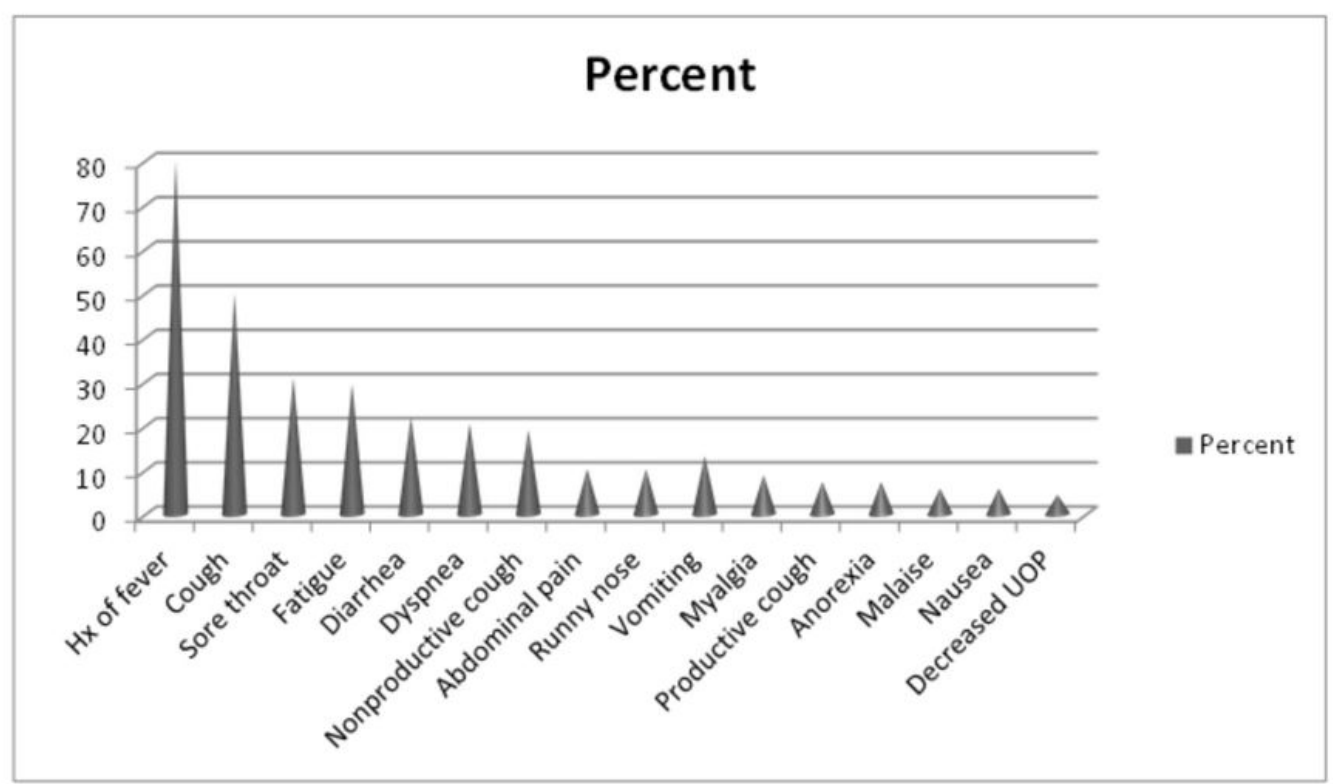

\section{Figure 2}

Distributional diagram of symptoms in patients with covid-19 nephropathy. 


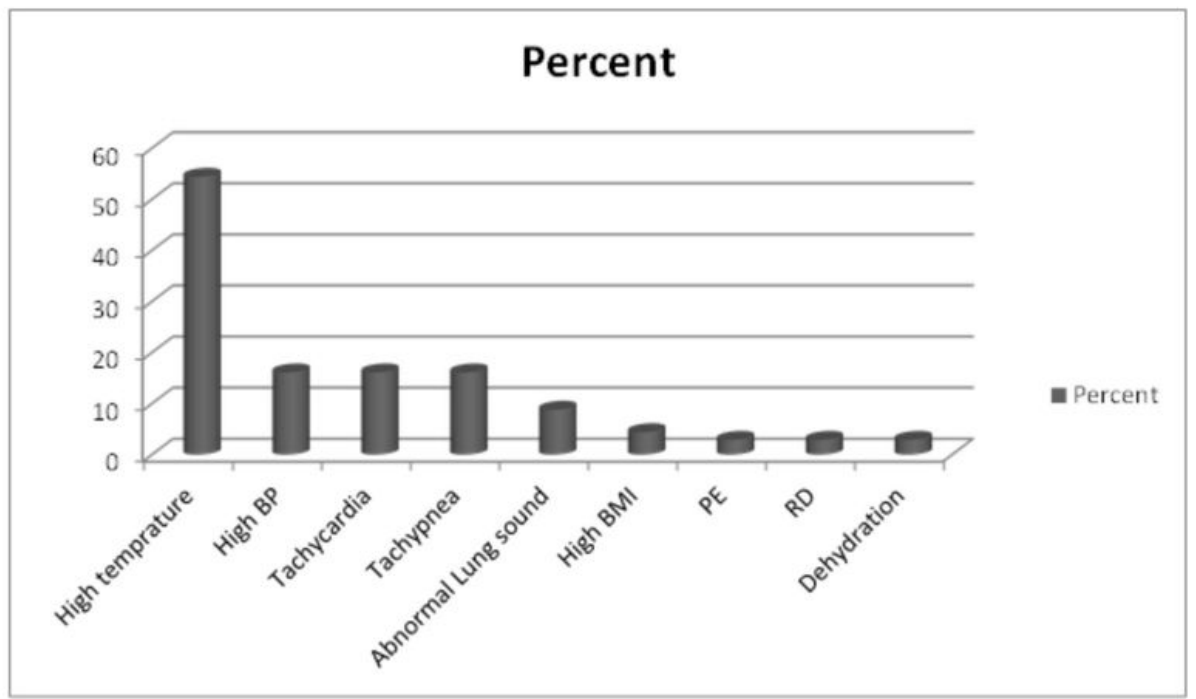

Figure 3

Distributional diagram of signs in patients with covid-19 nephropathy. 


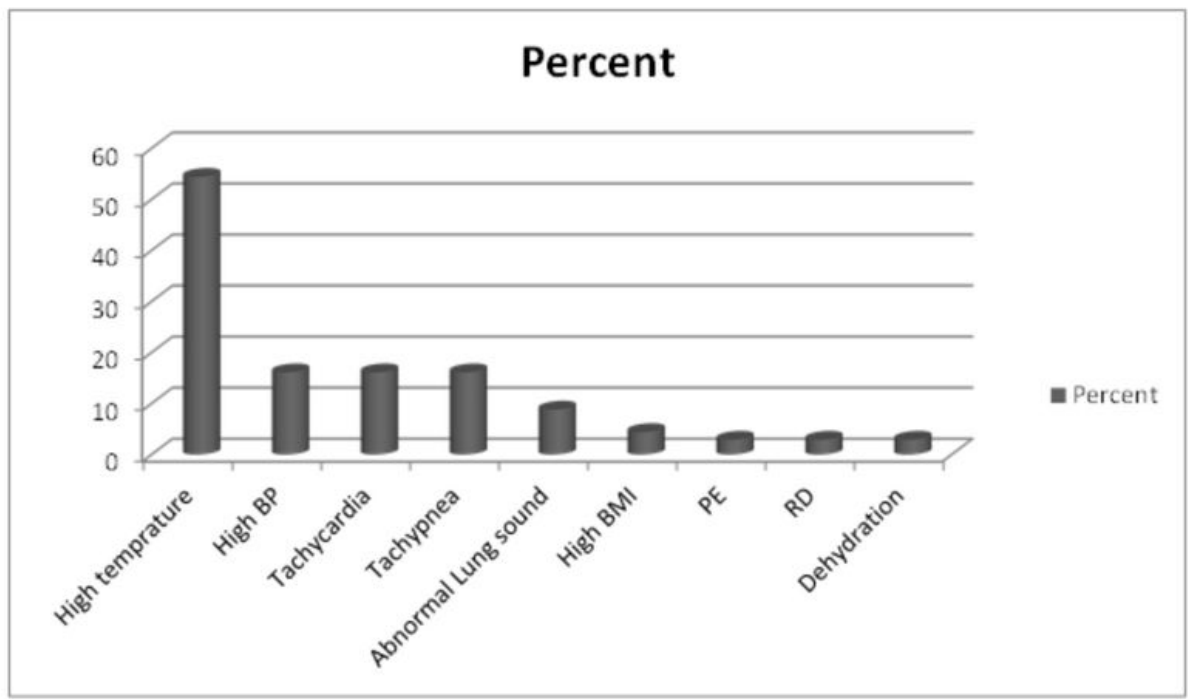

Figure 3

Distributional diagram of signs in patients with covid-19 nephropathy. 


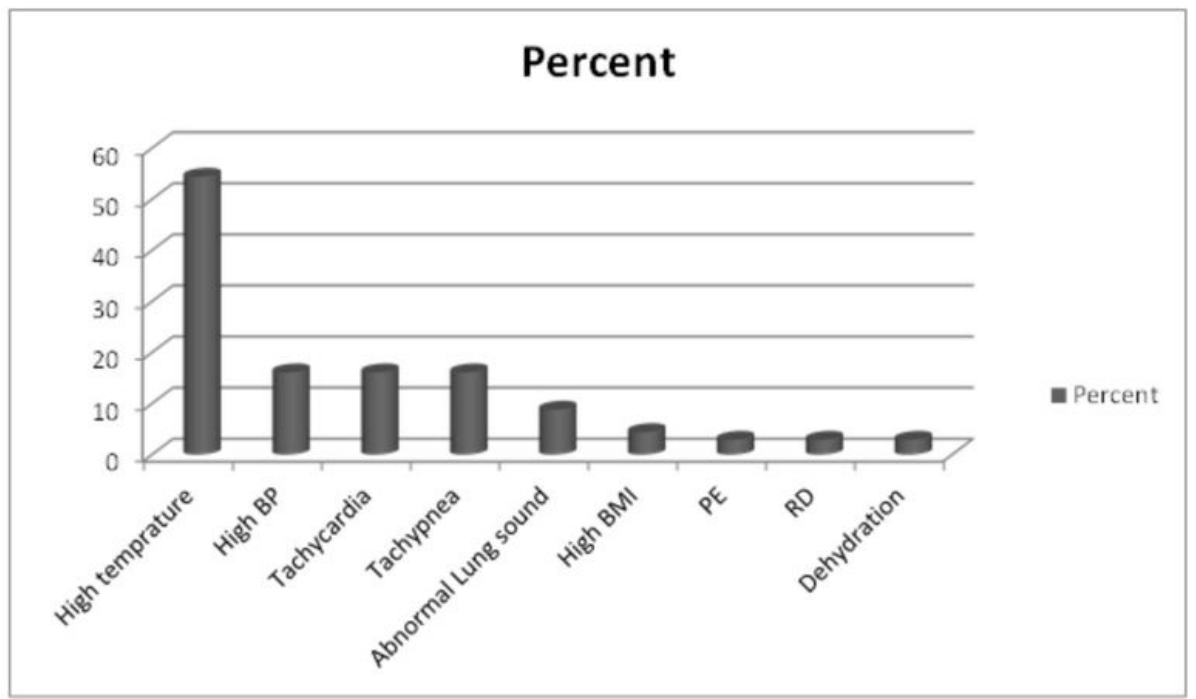

Figure 3

Distributional diagram of signs in patients with covid-19 nephropathy. 


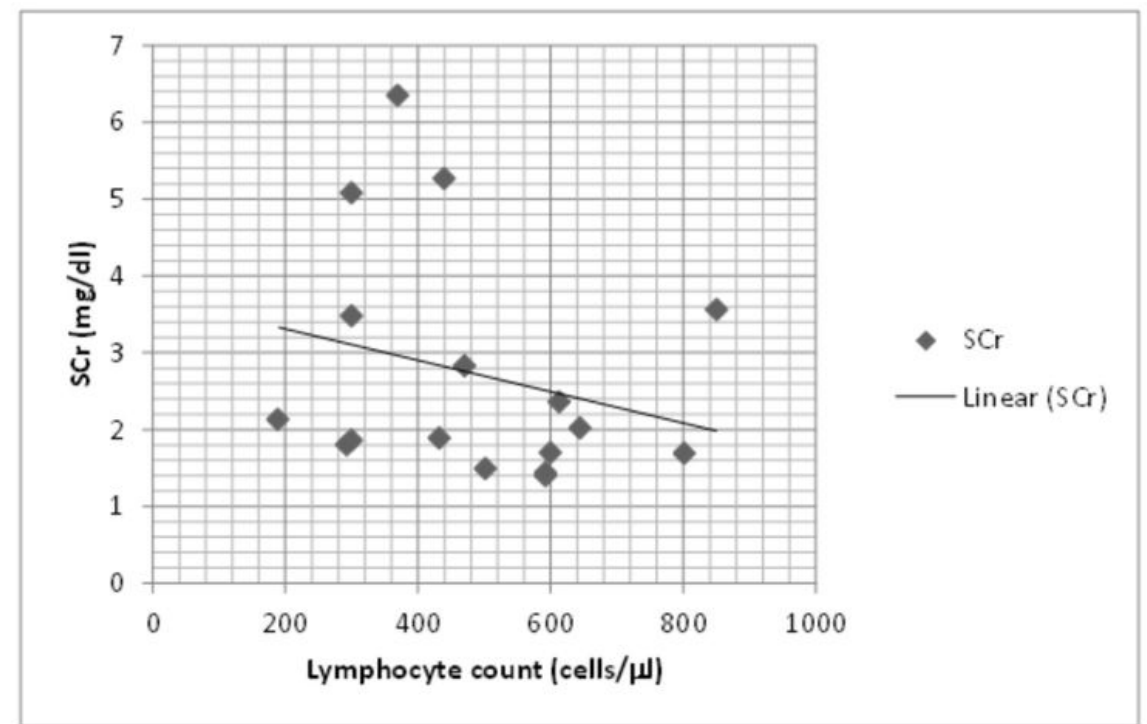

\section{Figure 4}

Distributional diagram of correlation between lymochytopenia and serum creatinine in covid-19 nephropathy. 


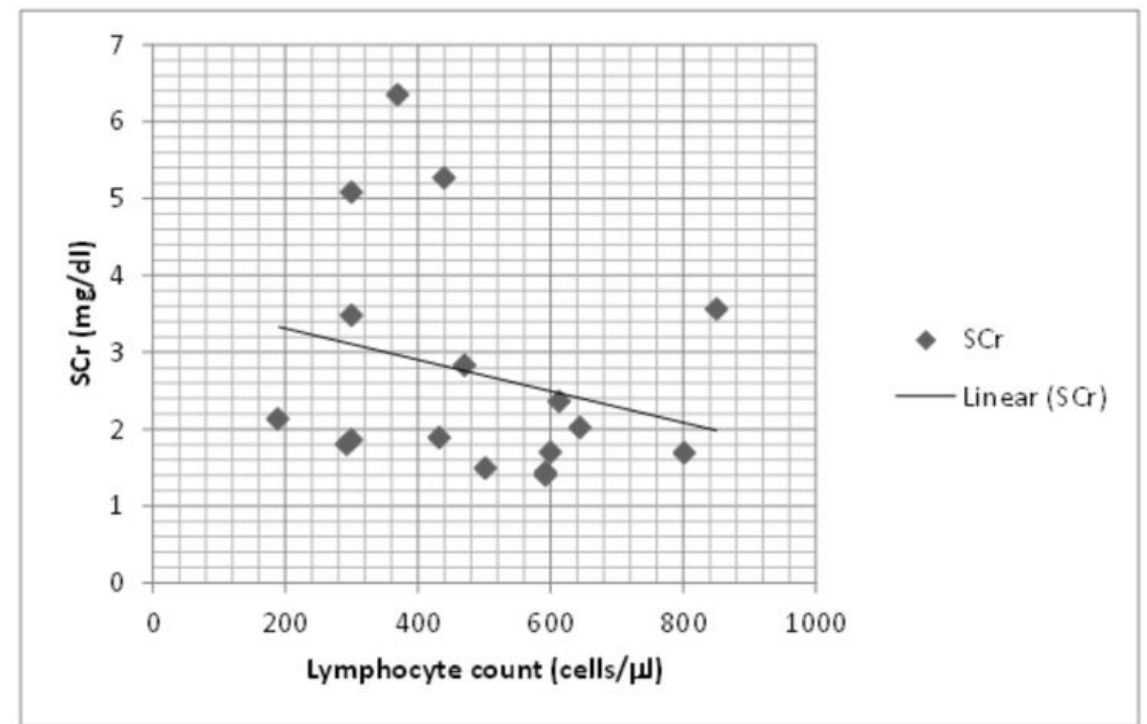

\section{Figure 4}

Distributional diagram of correlation between lymochytopenia and serum creatinine in covid-19 nephropathy. 


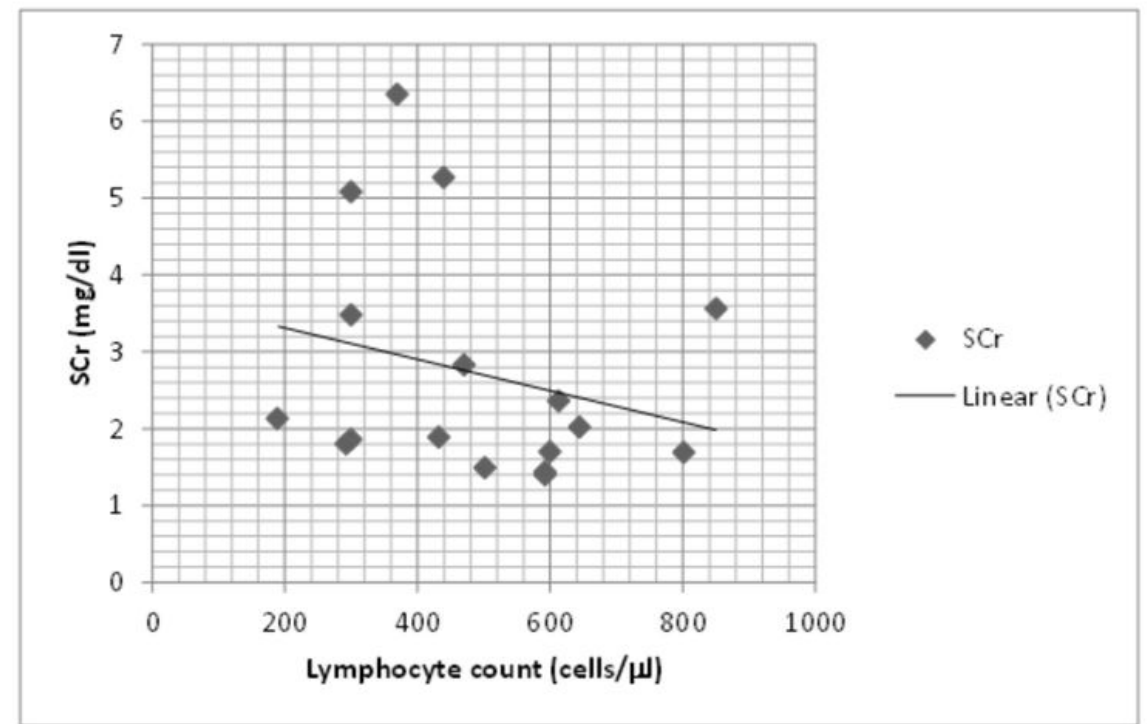

\section{Figure 4}

Distributional diagram of correlation between lymochytopenia and serum creatinine in covid-19 nephropathy. 


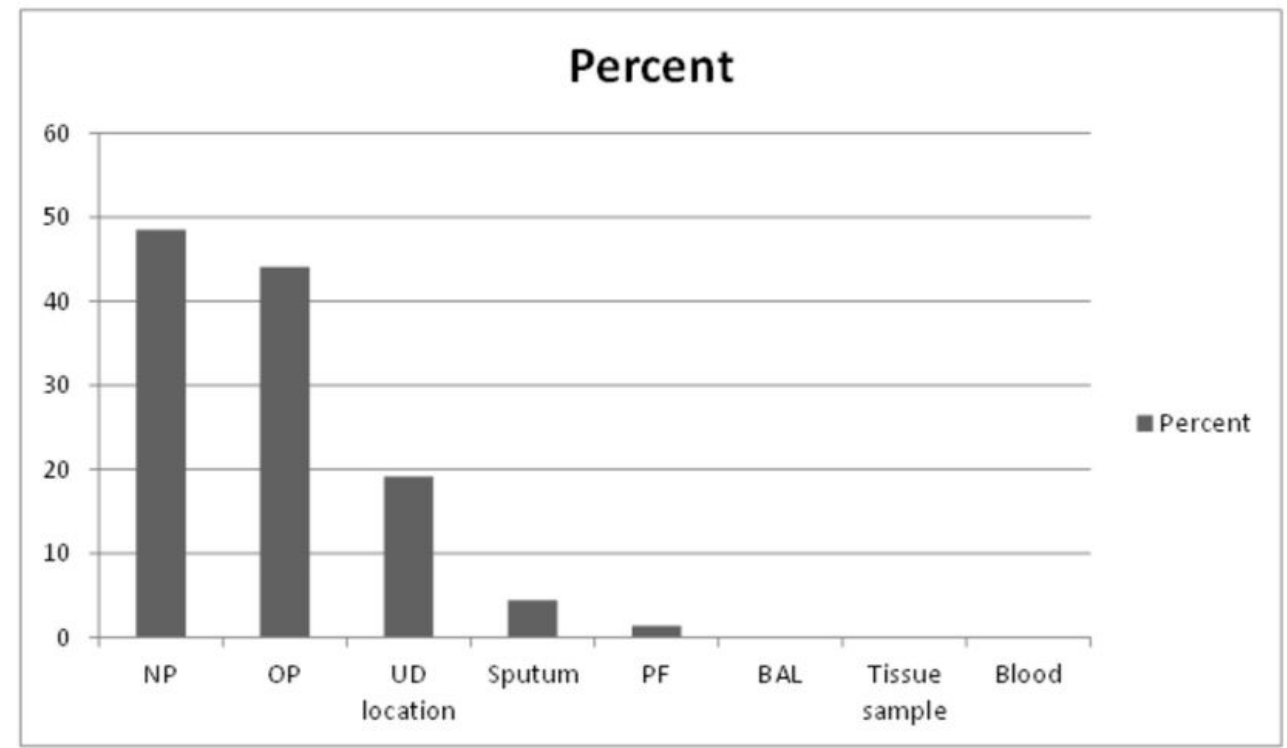

\section{Figure 5}

Distributional diagram of patients with positive covid-19 tests from different sites. NP, nasopharyngeal swab, OP, oropharyngeal swab, PF, peritoneal fluid, UD location, undetermined location. 


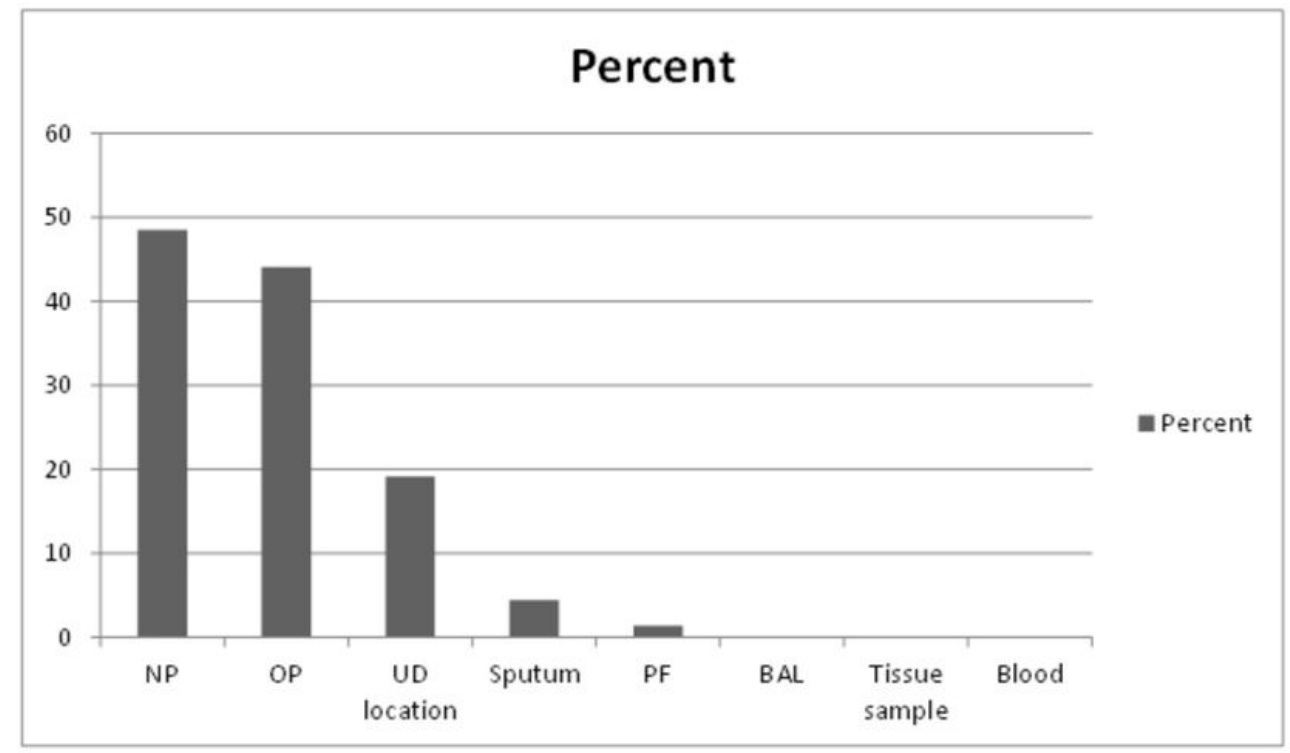

\section{Figure 5}

Distributional diagram of patients with positive covid-19 tests from different sites. NP, nasopharyngeal swab, OP, oropharyngeal swab, PF, peritoneal fluid, UD location, undetermined location. 


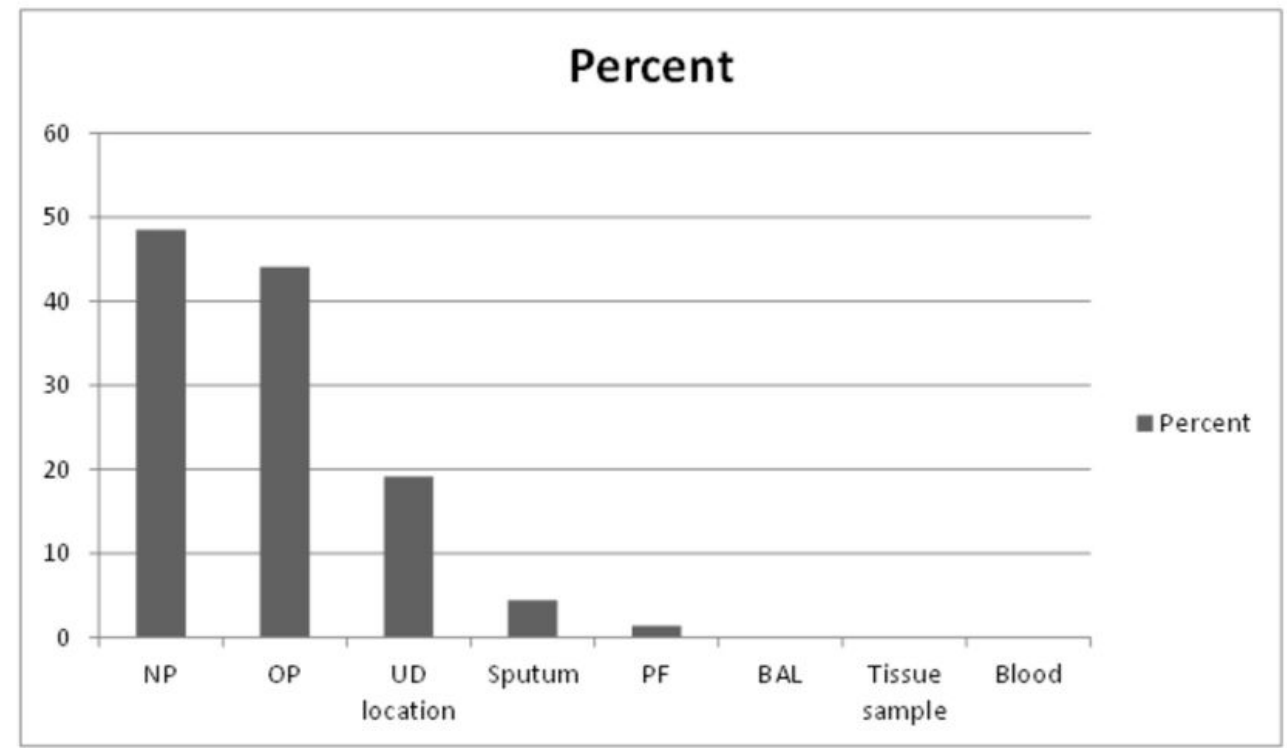

\section{Figure 5}

Distributional diagram of patients with positive covid-19 tests from different sites. NP, nasopharyngeal swab, OP, oropharyngeal swab, PF, peritoneal fluid, UD location, undetermined location. 


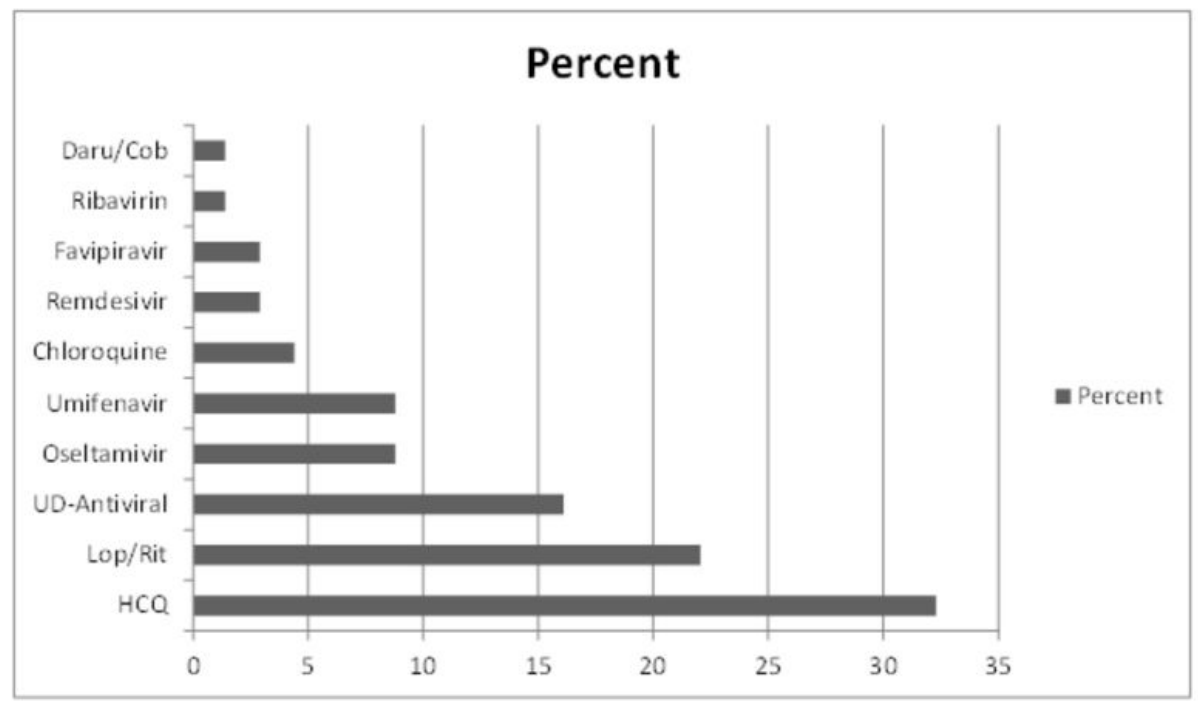

\section{Figure 6}

Diagrammal distribution of different antiviral therapy in patients of covid-19 nephropathy. 


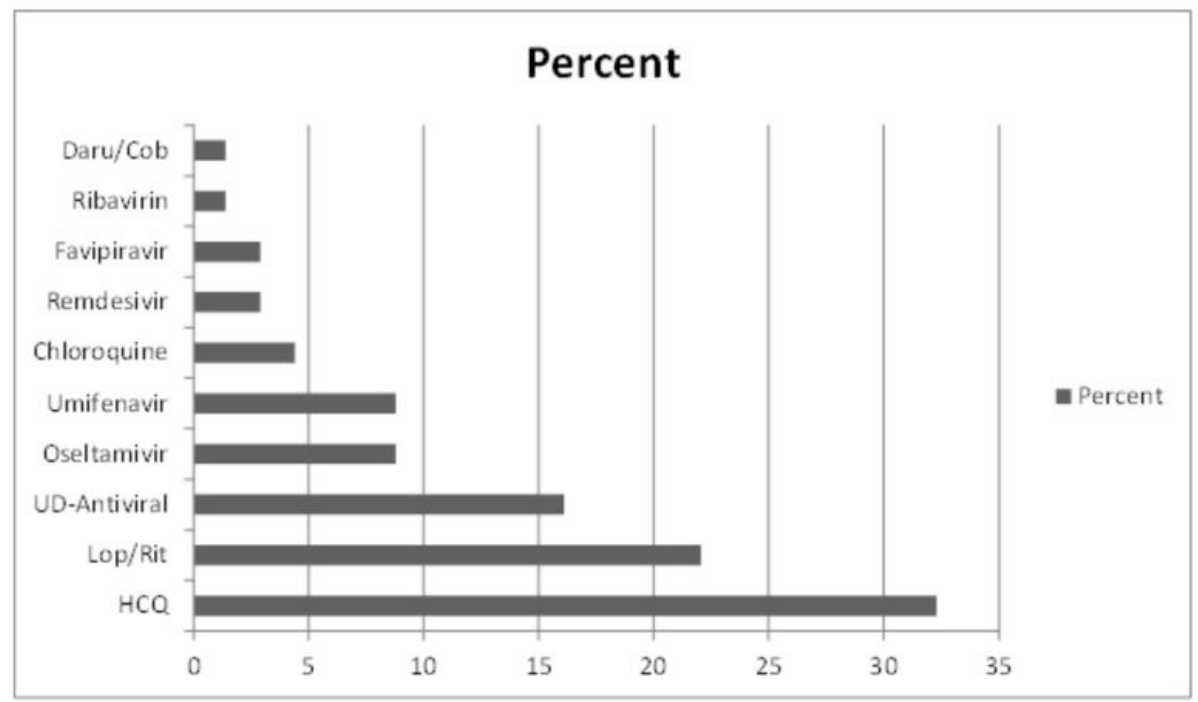

\section{Figure 6}

Diagrammal distribution of different antiviral therapy in patients of covid-19 nephropathy. 


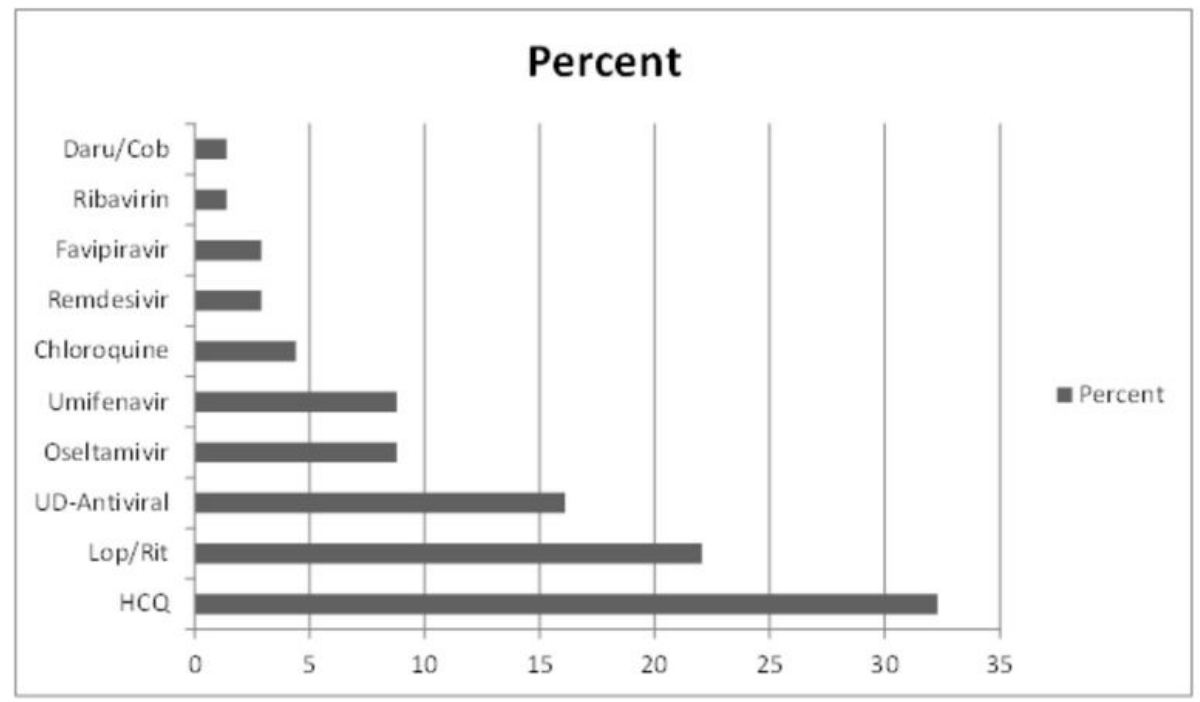

\section{Figure 6}

Diagrammal distribution of different antiviral therapy in patients of covid-19 nephropathy. 


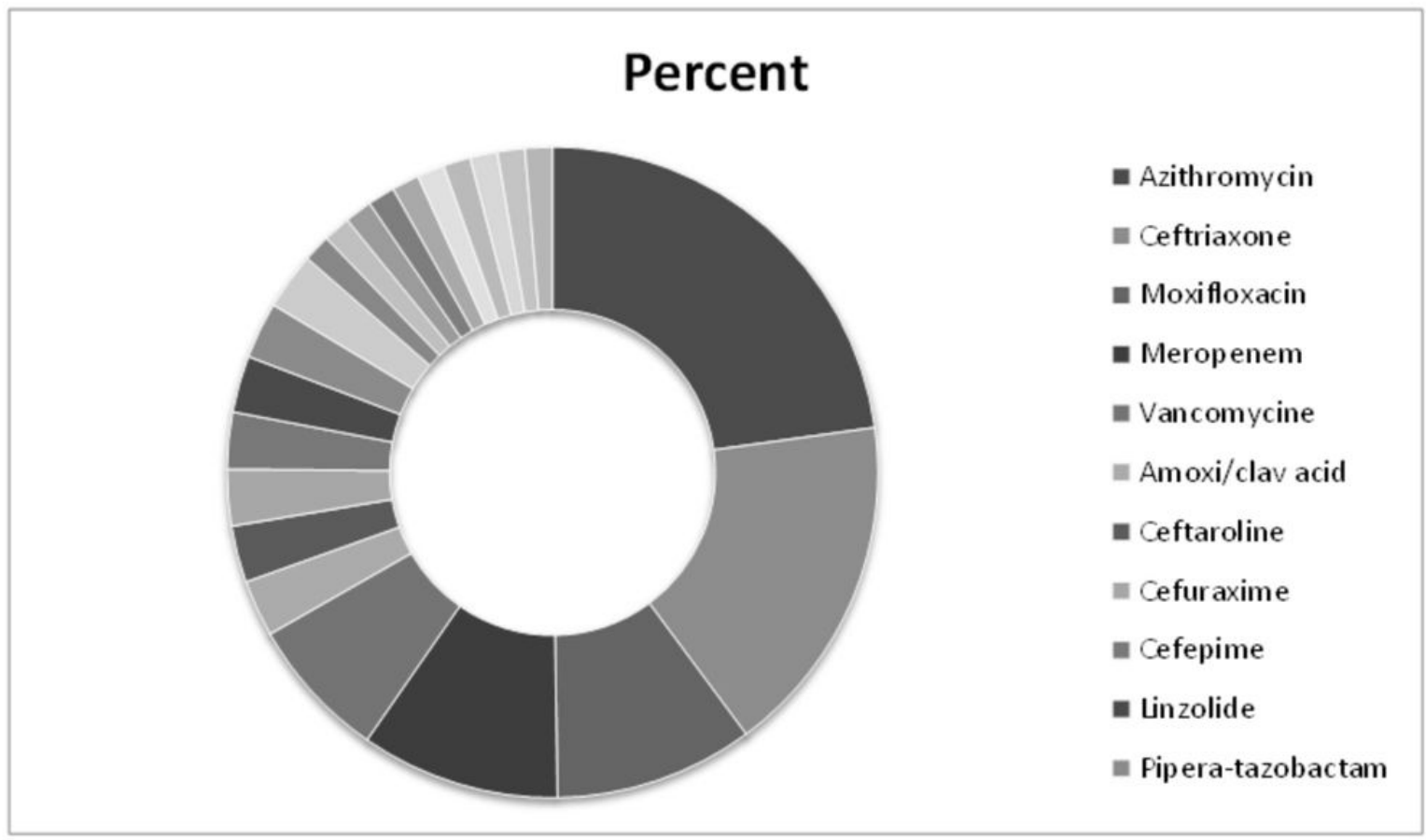

Figure 7

Diagrammal distribution of different antibiotic therapy in patients of covid-19 nephropathy. 


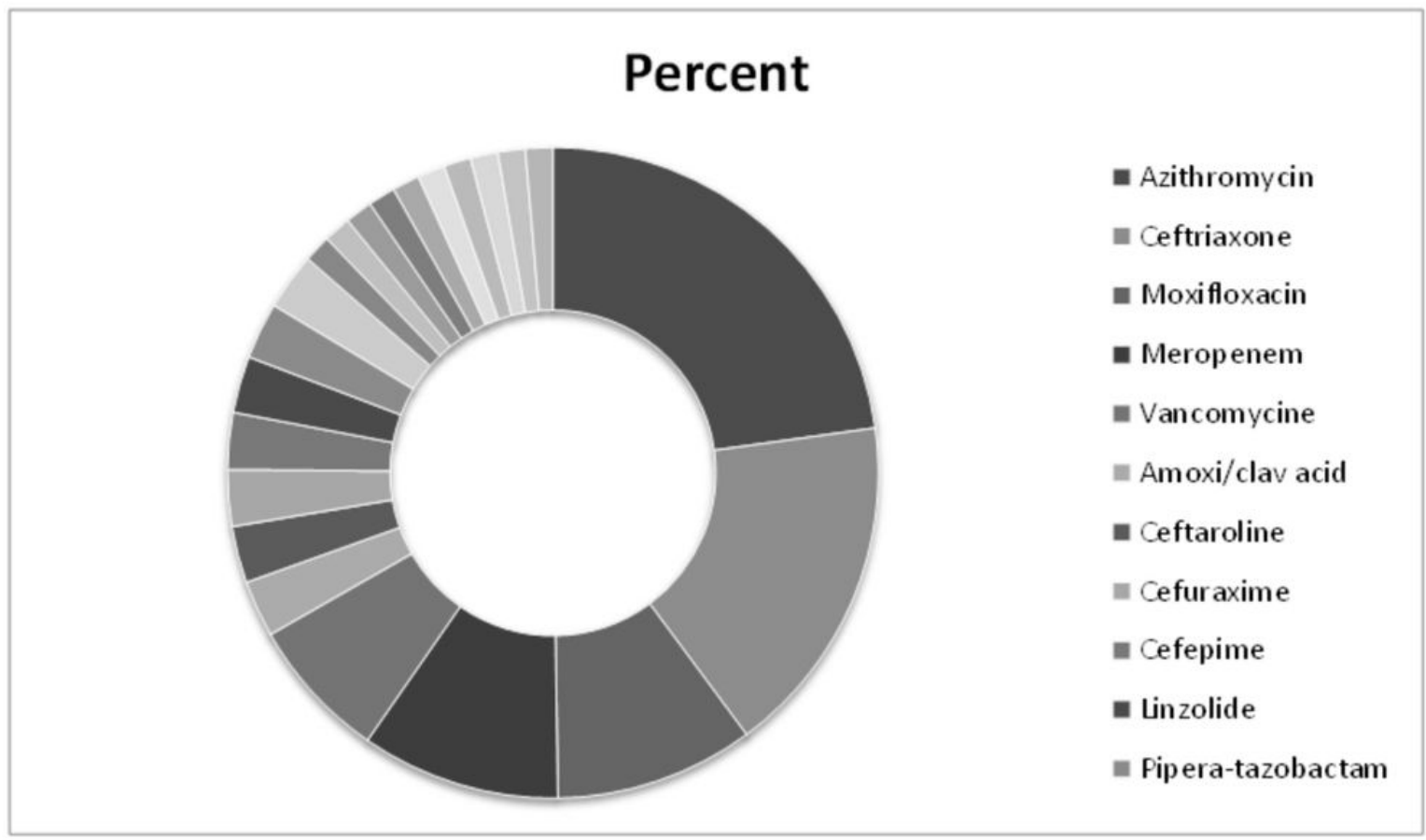

Figure 7

Diagrammal distribution of different antibiotic therapy in patients of covid-19 nephropathy. 


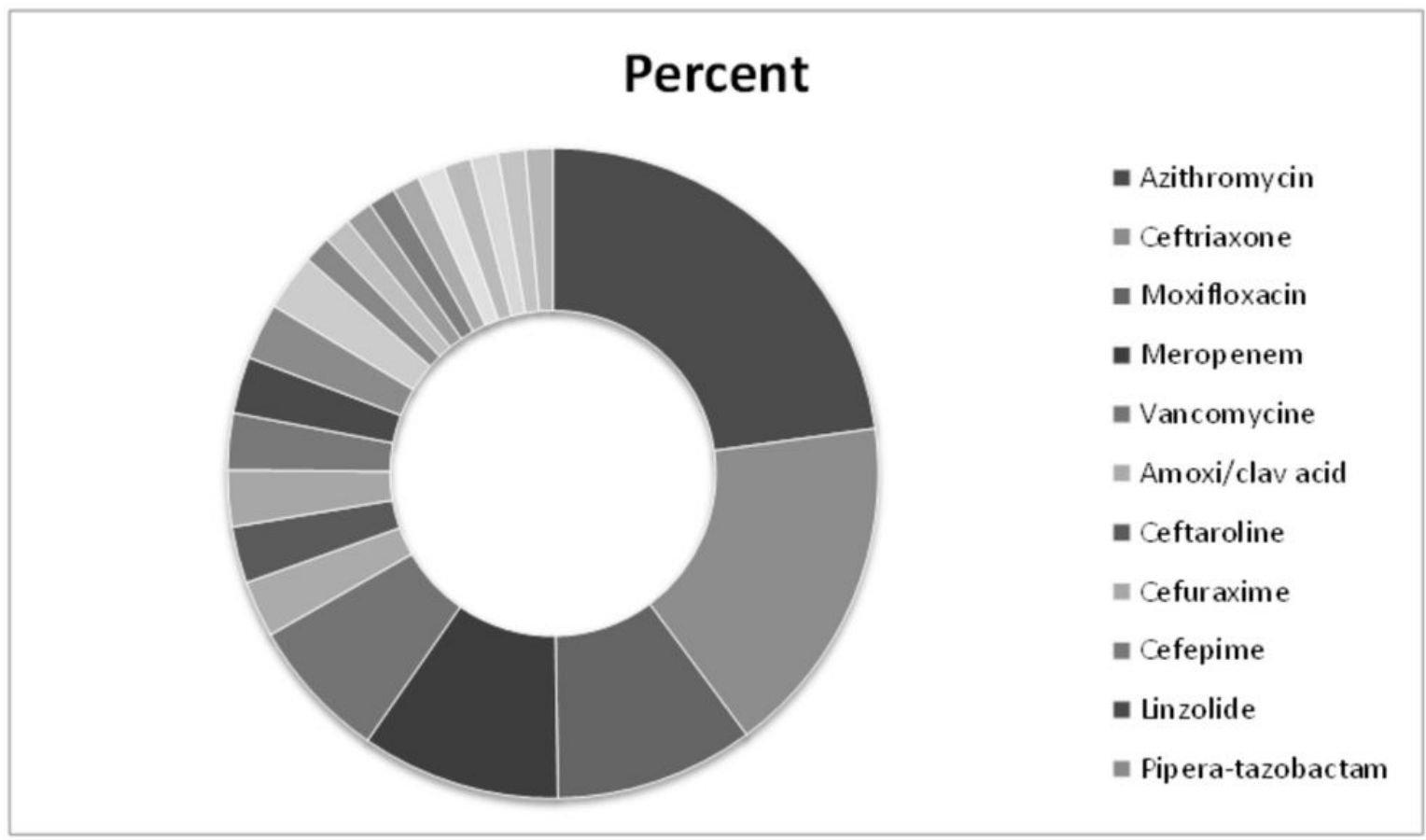

Figure 7

Diagrammal distribution of different antibiotic therapy in patients of covid-19 nephropathy. 


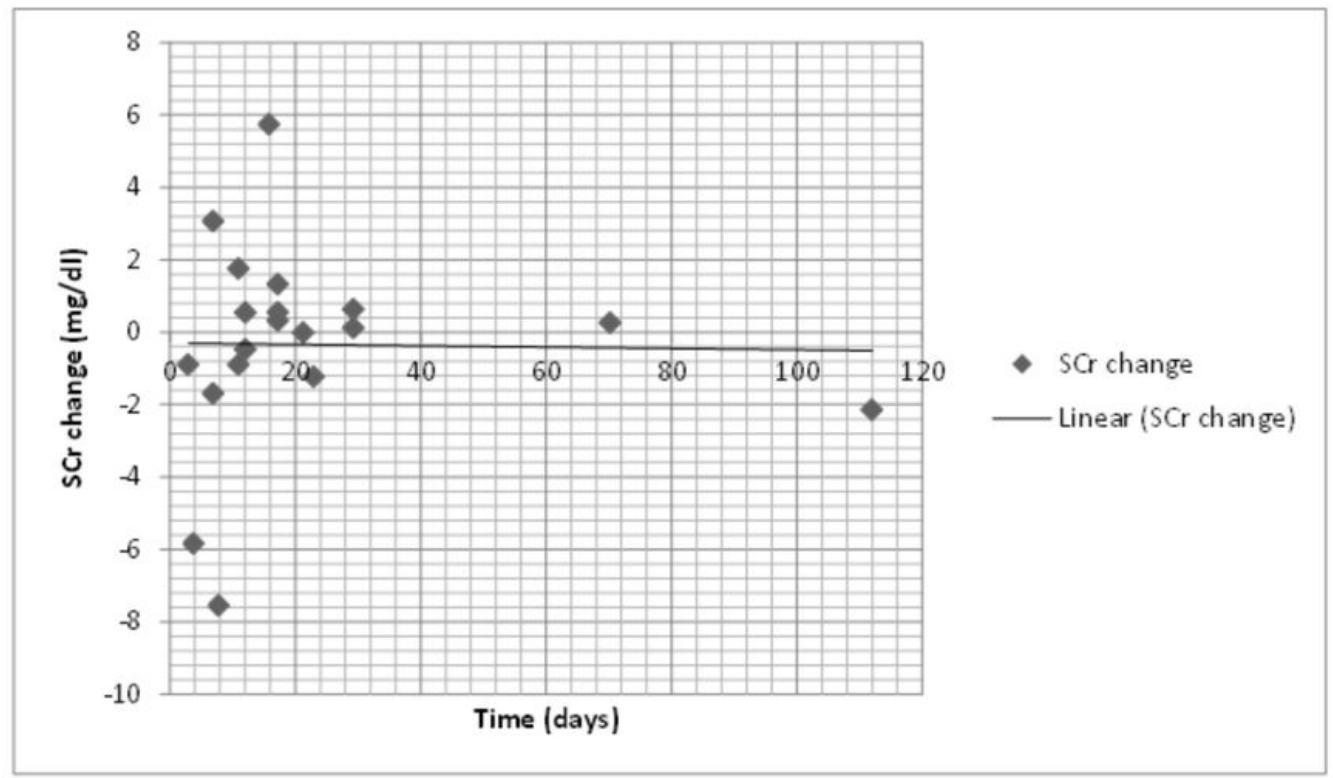

\section{Figure 8}

Correlation between serum creatinine change and time of emergent acute kidney injury, acute kidney disease in covid-19 nephropathy. 


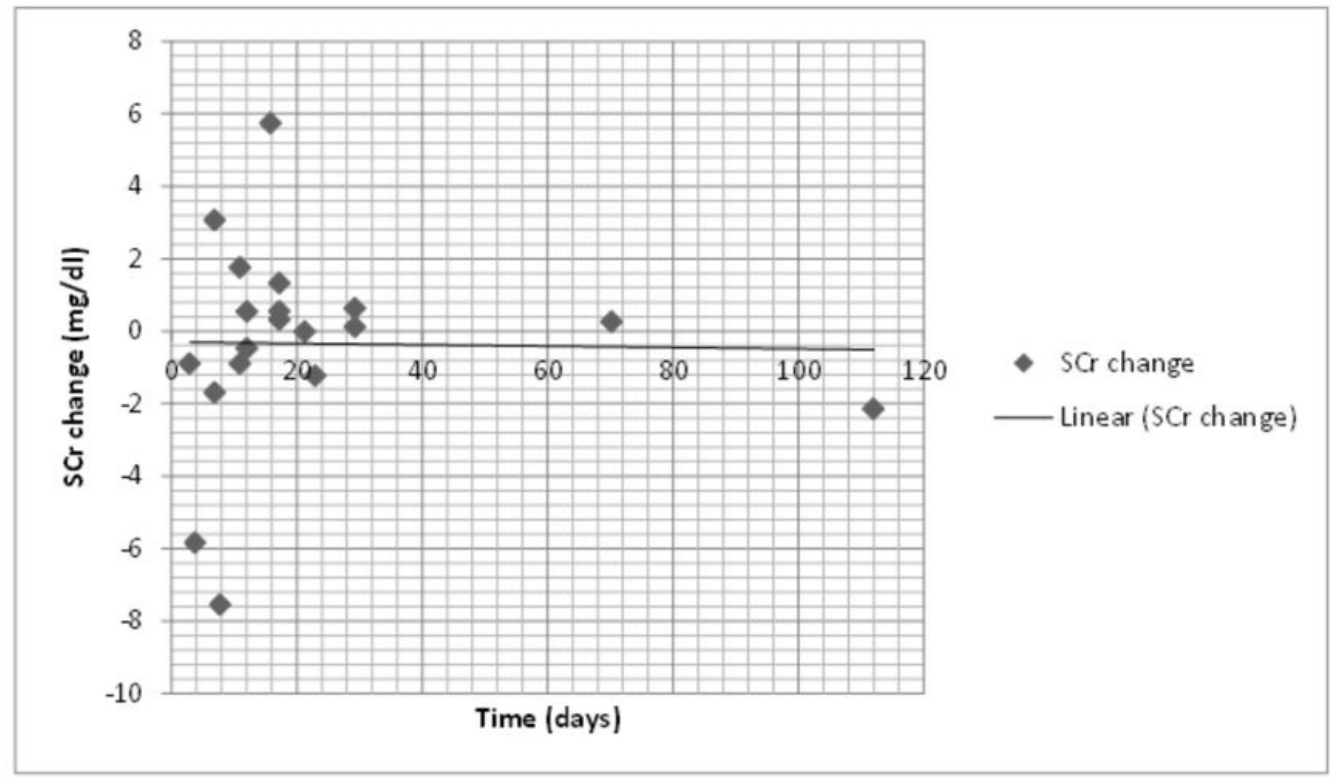

\section{Figure 8}

Correlation between serum creatinine change and time of emergent acute kidney injury, acute kidney disease in covid-19 nephropathy. 


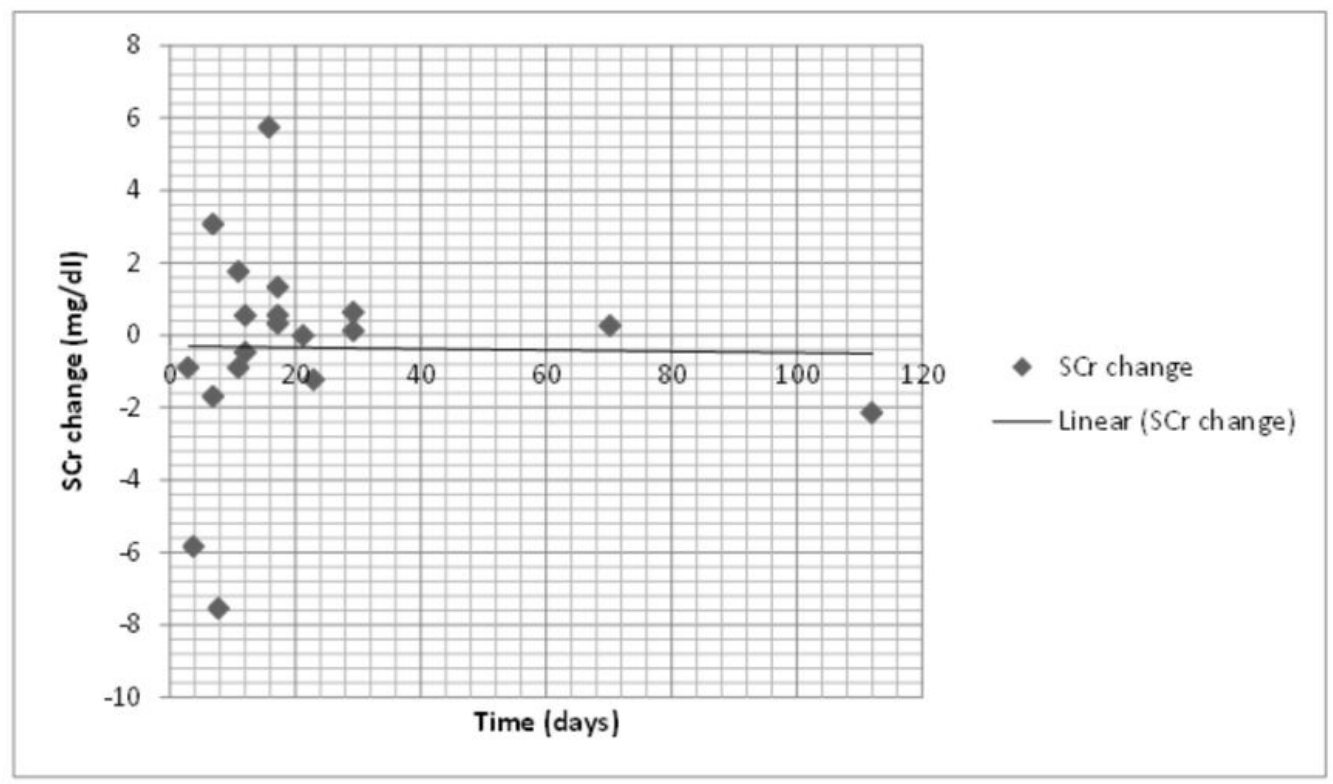

\section{Figure 8}

Correlation between serum creatinine change and time of emergent acute kidney injury, acute kidney disease in covid-19 nephropathy.

\section{Supplementary Files}

This is a list of supplementary files associated with this preprint. Click to download.

- Tables1a.docx

- Tables1a.docx

- Tables1a.docx

- Tables1b.docx

- Tables1b.docx

- Tables1b.docx

- Tables1c.docx

- TableS1c.docx

- Tables1c.docx

- Tables1d.docx

- Tables1d.docx

- Tables1d.docx

- Tables2.docx

- Tables2.docx

- Tables2.docx 
- Tables3a.docx

- Tables3a.docx

- Tables3a.docx

- Tables3b.docx

- Tables3b.docx

- Tables3b.docx

- Tables3c.docx

- TableS3c.docx

- Tables3c.docx

- Tables3d.docx

- Tables3d.docx

- Tables3d.docx

- Tables3e.docx

- Tables3e.docx

- Tables3e.docx

- Tables3f.docx

- Tables3f.docx

- Tables3f.docx

- Tables3g.docx

- TableS3g.docx

- Tables3g.docx

- Tables4a.docx

- Tables4a.docx

- Tables4a.docx

- Tables4b.docx

- Tables4b.docx

- Tables4b.docx

- Tables5a.docx

- Tables5a.docx

- Tables5a.docx

- Tables5b.docx

- Tables5b.docx

- Tables5b.docx

- TableS5c.docx

- TableS5c.docx

- Tables5c.docx

- Tables5d.docx

- Tables5d.docx

- Tables5d.docx

- Tables5e.docx

- Tables5e.docx

- Tables5e.docx

- Tables5f.docx

- Tables5f.docx

- Tables5f.docx

- TableS5g.docx

- TableS5g.docx

- TableS5g.docx

- Tables5h.docx

- Tables5h.docx 
- Tables5h.docx

- Tables5i.docx

- Tables5i.docx

- Tables5i.docx

- Tables5l.docx

- Tables5l.docx

- Tables5l.docx

- Tables5m.docx

- Tables5m.docx

- Tables5m.docx

- TableS5n.docx

- Tables5n.docx

- TableS5n.docx

- Tables5o.docx

- TableS5o.docx

- TableS5o.docx

- Tables6.docx

- Tables6.docx

- Tables6.docx

- Tables7a.docx

- Tables7a.docx

- Tables7a.docx

- Tables7b.docx

- Tables7b.docx

- Tables7b.docx

- Tables7c.docx

- Tables7c.docx

- Tables7c.docx

- Tables7d.docx

- Tables7d.docx

- Tables7d.docx

- Tables7e.docx

- Tables7e.docx

- Tables7e.docx

- Tables7f.docx

- Tables7f.docx

- Tables7f.docx

- Tables7g.docx

- Tables7g.docx

- TableS7g.docx

- Tables7m.docx

- Tables7m.docx

- Tables7m.docx

- TableS7n.docx

- Tables7n.docx

- Tables7n.docx

- Tables8a.docx

- Tables8a.docx

- Tables8a.docx

- Tables8b.docx 
- Tables8b.docx

- Tables8b.docx

- Tables8c.docx

- Tables8c.docx

- Tables8c.docx

- Tables8d.docx

- Tables8d.docx

- Tables8d.docx 